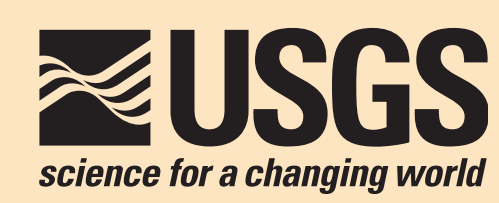

\title{
Opportunities and Needs for Mobile-Computing Technology to Support U.S. Geological Survey Fieldwork
}

Circular 1299

U.S. Department of the Interior

U.S. Geological Survey 


\section{Opportunities and Needs for Mobile-Computing Technology to Support U.S. Geological Survey Fieldwork}

By Nathan J. Wood and David L. Halsing

Circular 1299 


\section{U.S. Department of the Interior DIRK KEMPTHORNE, Secretary}

\section{U.S. Geological Survey Mark D. Myers, Director}

\section{U.S. Geological Survey, Reston, Virginia, 2006}

For product and ordering information:

World Wide Web: http://www.usgs.gov/pubprod/

Telephone: 1-888-ASK-USGS

For more information on the USGS - the Federal source for science about the Earth, its natural and living resources, natural hazards, and the environment:

World Wide Web: http://www.usgs.gov

Telephone: 1-888-ASK-USGS

Any use of trade, product, or firm names is for descriptive purposes only and does not imply endorsement by the U.S. Government.

\section{Suggested citation:}

Wood, Nathan J., and Halsing, David L., 2006, Opportunities and needs for mobile computing technology to support U.S. Geological Survey fieldwork: Reston, Virginia, U.S. Geological Survey Circular 1299, 24 p.

Although this report is in the public domain, permission must be secured from the individual copyright owners to reproduce any copyrighted material contained within this report.

\section{Cataloging-in-Publication data are on file with the Library of Congress}

Produced in the Western Region, Menlo Park, California

Manuscript approved for publication, May 25, 2006

Text edited by George A. Havach

Layout and design by Stephen L. Scott 


\section{Contents}

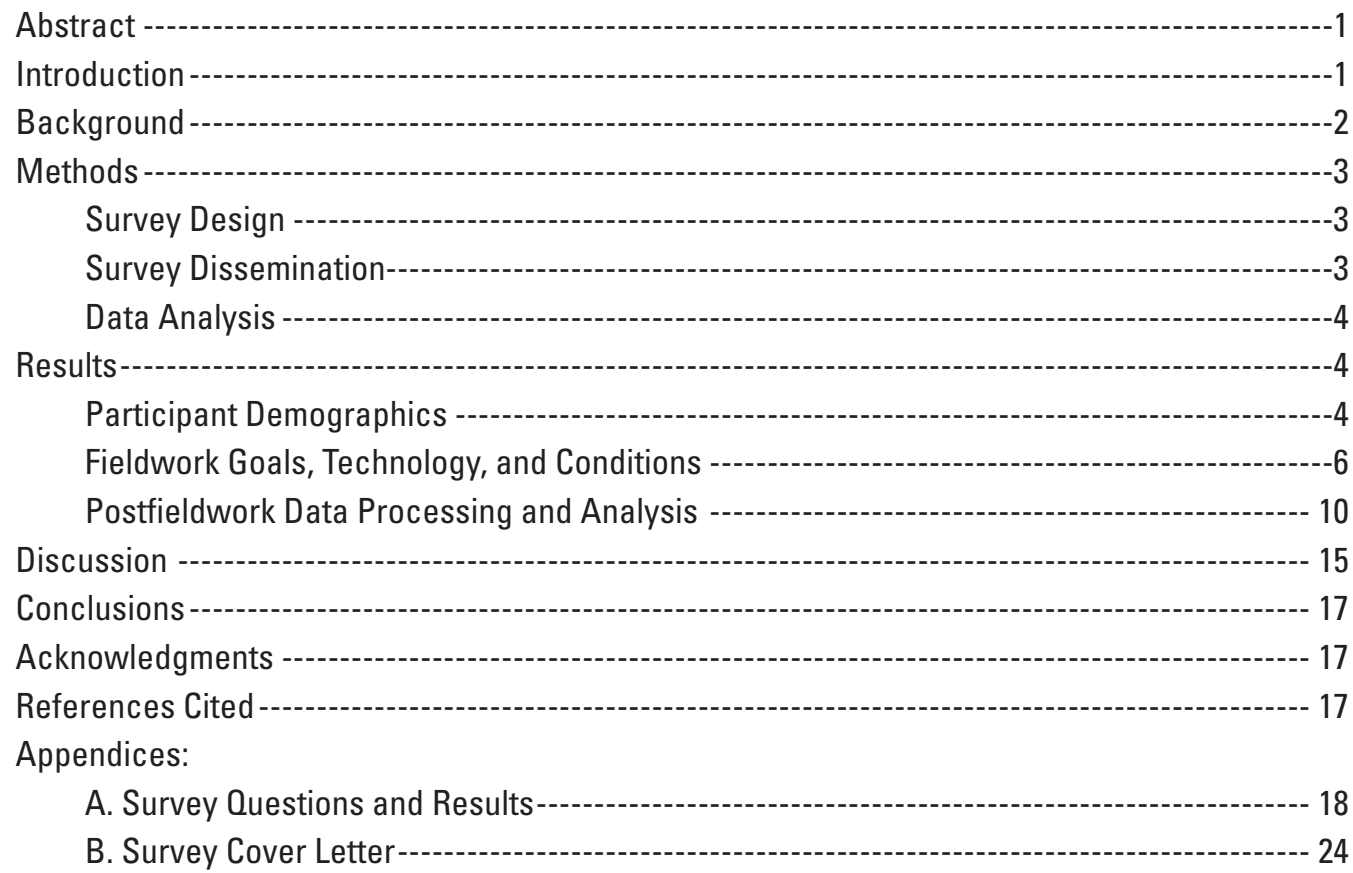

\section{Figures}

1. Photographs showing examples of hand-held mobile-computing technology ------------------2

2. Photographs showing examples of portable mobile-computing technology --------------------3

3. Histogram of respondents' numbers of years of field research ----------------------------5

\section{Tables}

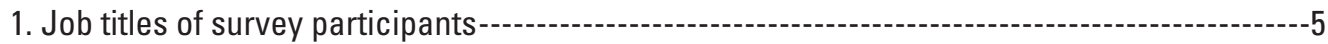

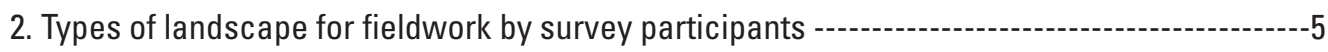

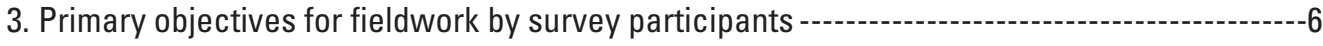

4. Types of observation made and sample taken by survey participants ---

5. Environmental features mapped in the field by survey participants-----------------------------7

6. Mapping of environmental features in the field by survey participants,

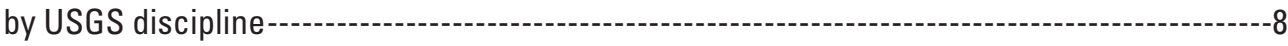

7. Uses of mobile-computing technology in the field by survey participants-----------------------8

8. Type, purpose, and scale of maps used in the field by survey participants -----------------8

9. Primary uses of mobile-computing technology by survey participants ----------------------9

10. Aspects of fieldwork conditions reported by survey participants ---------------------- 10

11. Estimated hours worked by and salary paid to survey participants to conduct

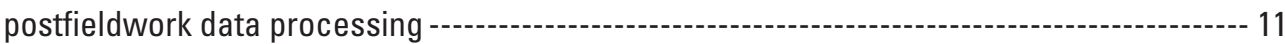


12. Salary table for Federal employees used to estimate salary paid to survey participants to conduct postfieldwork data processing--- 11

13. Uses of GIS by survey participants --- 12

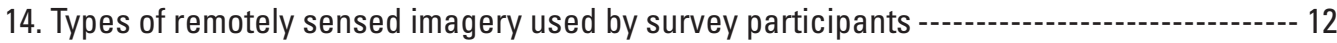

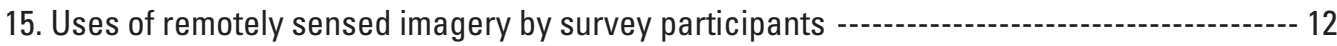

16. Uses of geospatial datasets by survey participants --- 13

17. Correlation matrix between field activities and use of specific technologies ----------------- 14

18. Mean numbers of years of USGS field experience between who answered "Yes" and "No" on field activities and use of specific technologies -------------------- 16

19. Results of statistical $t$ test comparing years of USGS field experience with field activities and use of specific technologies --- 17 


\title{
Opportunities and Needs for Mobile-Computing Technology to Support U.S. Geological Survey Fieldwork
}

\author{
By Nathan J. Wood and David L. Halsing
}

\section{Abstract}

To assess the opportunities and needs for mobile-computing technology at the U.S. Geological Survey (USGS), we conducted an internal, Internet-based survey of bureau scientists whose research includes fieldwork. In summer 2005, 144 survey participants answered 65 questions about fieldwork activities and conditions, technology to support field research, and postfieldwork data processing and analysis. Results suggest that some types of mobile-computing technology are already commonplace, such as digital cameras and Global Positioning System (GPS) receivers, whereas others are not, such as personal digital assistants (PDAs) and tablet-based personal computers (tablet PCs). The potential for PDA use in the USGS is high: 97 percent of respondents record field observations (primarily environmental conditions and waterquality data), and 87 percent take field samples (primarily water-quality data, water samples, and sediment/soil samples). The potential for tablet PC use in the USGS is also high: 59 percent of respondents map environmental features in the field, primarily by sketching in field notebooks, on aerial photographs, or on topographic-map sheets. Results also suggest that efficient mobile-computing-technology solutions could benefit many USGS scientists because most respondents spend at least 1 week per year in the field, conduct field sessions that are least 1 week in duration, have field crews of one to three people, and typically travel on foot about $1 \mathrm{mi}$ from their field vehicles. By allowing researchers to enter data directly into digital databases while in the field, mobile-computing technology could also minimize postfieldwork data processing: 93 percent of respondents enter collected field data into their office computers, and more than 50 percent spend at least 1 week per year on postfieldwork data processing. Reducing postfieldwork data processing could free up additional time for researchers and result in cost savings for the bureau. Generally, respondents support greater use of mobile-computing technology at the USGS and are interested in training opportunities and further discussions related to data archiving, access to additional digital data types, and technology development.

\section{Introduction}

Although such technology as satellite imagery has greatly improved regional data collection, many U.S. Geo- logical Survey (USGS) scientists rely on manual data entries, sketches, and paper-map corrections in the course of their fieldwork. Emerging mobile-computing technologies, such as personal digital assistants (PDAs) and tablet-based personal computers (tablet PCs), can potentially simplify and improve field data collection and postfieldwork data processing and analysis in USGS research. Using this technology, USGS scientists could devote less time and energy to the logistic concerns of fieldwork and data management. For research initiatives that have data-collection protocols, such as regional water-quality monitoring, mobile-computing technologies could run integrated data-collection templates. In addition to simplifying data collection, mobile-computing technology may also alter field efforts by enabling researchers to create dynamic or adaptive sampling designs.

The use of mobile-computing technology to facilitate fieldwork is increasing at the USGS, including the Water Resources Discipline's Field Computer Interest Group's use of PDAs in water-quality monitoring (URL http://water. usgs.gov/usgs/nwis/FCIG/fcig_index.html) and the Geologic Discipline's annual workshops on digital techniques related to geologic mapping (Stoller, 2003). However, these and other bureau efforts related to mobile-computing technology (Pavlis and Little, 2001; Williams, 2001; Edmondo, 2002) may remain within specific disciplines, and other USGS scientists may not benefit. With no bureauwide technical-assistance group, individual researchers are devoting limited resources and time to technology development and implementation. Although individual use of mobile-computing technology is not new for some researchers, demand for bureau coordination and communication on mobile-computing technology development and implementation is increasing. In response, the USGS Geospatial Information Office (GIO), the USGS Western Ecological Research Center, and the USGS California Water Science Center jointly sponsored a PDA Workshop in San Diego, Calif., in November 2004 to (1) obtain an overview of how PDAs are currently being used for research and monitoring in the USGS and the Department of the Interior, (2) create a forum for PDA users throughout the USGS to meet and discuss common issues, and (3) determine the need for a bureau-level technical team to coordinate and promote mobile-computing technology to support USGS fieldwork.

To further the objectives of the 2004 USGS PDA Workshop, we have conducted a bureauwide issues and needs 
assessment to document current and potential use of mobilecomputing technology for USGS field data collection and mapping activities. An internal, Internet-based survey was used to collect data for this study, with questions about fieldwork activities and conditions, technology to support USGS fieldwork, and postfieldwork data processing and analysis. This report summarizes the results of this survey, as well as suggesting potential next steps related to the use and effectiveness of mobile-computing technology in USGS research. This report is intended to (1) reveal opportunities for technology sharing, (2) foster a community of technology developers and users, (3) identify new areas for mobilecomputing-technology development and implementation, and (4) encourage a coordinated bureauwide effort to further evaluate mobile-computing technology to support USGS fieldwork.

\section{Background}

For those who are unfamiliar with mobile-computing technology, we provide a short overview of the two most common types-PDAs and tablet PCs. Although laptop PCs can be considered mobile devices, we focus specifically on hand-held devices that can be used easily while standing.

A PDA is a hand-held device that combines a PC, cellular phone, an e-mail client, and (or) a personal organizer (fig. 1). Unlike laptop computers with keyboards, most PDAs use a stylus, a penlike instrument for tapping the screen to input information. Newer PDAs include both a stylus and a miniature keyboard designed primarily for input by one's thumbs. Since many PDAs can run full-featured databases, PDAs can be used to download data from field monitors and dataloggers. Currently, many PDAs have builtin Global Positioning System (GPS) receivers and can run geographic-information-system (GIS) software, allowing users to navigate, mark study sites, and collect georeferenced data.

Tablet PCs are laptop PCs that can be manipulated to resemble a writing pad (fig. 2). In addition to a full-size keyboard and built-in mouse, tablet PCs are equipped with a touch-sensitive screen designed to interact with a digital pen that operates like a combined computer mouse and stylus. These configurations allow the user to use the tablet PC while standing up and cradling the device. A tablet PC also has handwriting- and voice-recognition software, allowing users to capture information in ways that best suit them. A full screen and large data-storage capacity (currently max $80 \mathrm{~GB}$ ) allows users to transport and access high-resolution data and imagery in the field. Within a GIS environment, a tablet PC allows a user to use the digital pen to access data, attach notes to geographic locations, and delineate boundaries. Creating boundaries, either as lines or polygons, directly in a GIS eliminates the need to later digitize the information, such as collected waypoints or sketches on a paper map.

When deciding which technology is appropriate, a fieldworker should relate the features of each device to the research objectives, field conditions, and budget of a project. With full-featured databases but small screens and small data-storage capacities, PDAs are ideal for downloading data, creating points on a map, recording audio notes, and collecting data by way of predetermined dropdown menus. With greater computing power, a digital pen, and a full-size screen, a tablet PC can do all of these things plus offer the full functionality of a laptop computer, as well as the ability to write digital field notes and to draw polygons when delineating boundaries. In comparison with a PDA, however, a tablet $\mathrm{PC}$ has a shorter battery life, is more expensive, and may offer rather more functionality than a fieldworker needs.
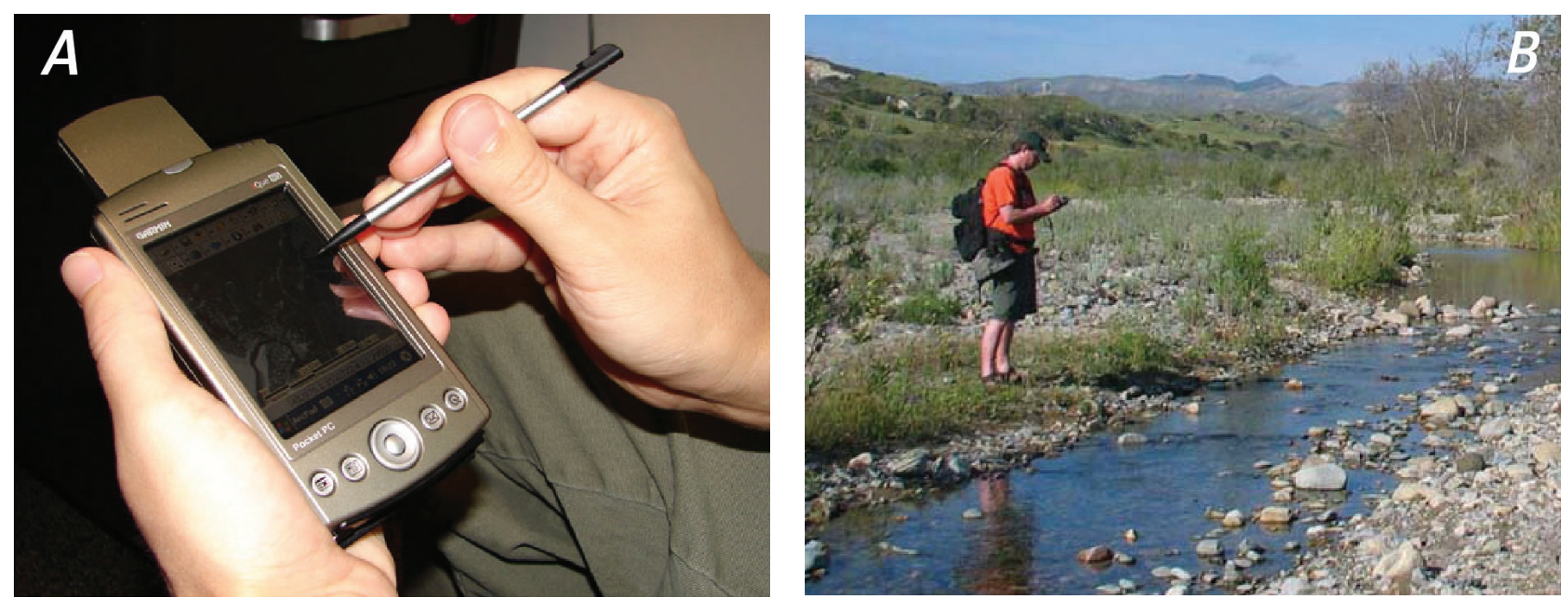

Figure 1. Examples of hand-held mobile-computing technology. $A$, Portable digital assistant (PDA). $B$, Scientist using a PDA in the field. 


\section{Methods}

\section{Survey Design}

This study is based on data collected from an Internetbased survey conducted in summer 2005 that consisted of 65 questions about (1) the goals and logistic aspects of USGS fieldwork, (2) postfieldwork data processing and analysis, and (3) survey-participant demographics. The survey was a mix of scripted and open-ended questions; out of 65 questions, 37 offered the respondent a choice of predetermined answers, such as "Yes" or "No," and the other 28 allowed the respondent to type a response directly into a text box. The full set of survey questions and responses is provided in appendix A.

We designed the survey Web site so that a respondent saw only one question at a time. Questions were contingent and nested, wherein a respondent answering "Yes" to an initial question would then see a set of more detailed, followup questions, whereas a respondent answering "No" to the same question would be routed past these followup questions to the next major question. This structure shortened the survey time for those respondents with nothing to add to a particular line of questioning, while extracting as much information and insight as possible out of others.

After a survey participant clicked or typed a response and clicked a "Submit" button for each question, the response was automatically entered into a temporary memory buffer. While taking the survey, a respondent had the opportunity to change previous responses, start over, or quit. The default selection for all questions was "No answer," allowing a respondent to proceed to the next question without answering. The entire set of responses was entered into a permanent database after a respondent completed the survey and actively clicked a final "Submit" button.
At the beginning of the survey, participants were notified that they would be asked for their name and contact information at the conclusion of the survey, but that this information was optional and that their responses would be counted even if they chose not to provide it. Contact information would be used by the USGS to begin to build a virtual community of interested mobile-computing-technology users and an archive of USGS scripts and tools that capitalize on mobile-computing technology. However, the survey stated upfront that responses to questions would be separated from contact information to protect a respondent's privacy and confidentiality.

\section{Survey Dissemination}

The survey was hosted on an internal USGS Web site. Our intent was to reach all individuals involved in field-based research at the USGS, including those who are currently using mobile-computing technology. USGS staff scientists and managers were notified about the survey and requested to respond in the following ways:

- $\quad$ E-mails with a survey cover letter (see app. B) were sent from the Geographic Analysis and Monitoring Program (Geography Discipline) and the Enterprise Information Program (Geospatial Information Office) to all USGS program coordinators and team leaders, who were asked to forward the information to the appropriate fieldworkers in their groups;

- A notice with a survey link was posted on the USGS internal Web site; and

- A notice in Western Exposure, a weekly electronic newsletter of the USGS Western Region, invited readers to respond to the survey and provided a link to the survey's Web site.
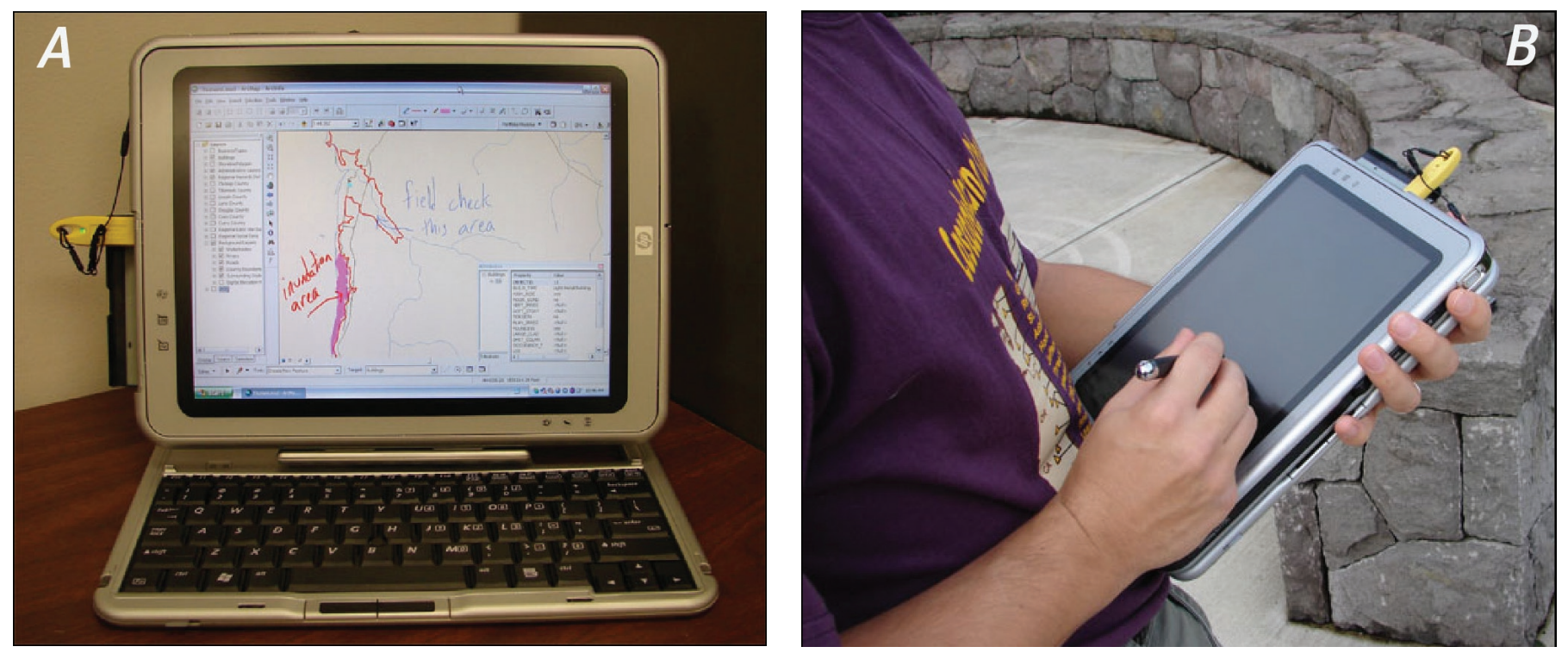

Figure 2. Examples of portable mobile-computing technology. $A$, Tablet-based personal computer (tablet PC). $B$, Use of a tablet PC with a stylus. 


\section{Data Analysis}

Analysis of the survey data varied, based on question type. For scripted questions (for example, "In which USGS region are you employed? (a) Western Region, (b) Central Region, (c) Eastern Region, (d) Headquarters"), we calculated the percentage of each option. For certain "Yes or No" questions, we performed statistical analysis to assess the degree of correlation and the strength of influences between several of the factors addressed in the survey. For example, we used statistical $t$ tests to check for significant differences in the mean numbers of years of field experience between groups of respondents who answered "Yes" or "No" to questions about their use of certain devices and (or) perform various field activities.

For open-ended questions, we grouped responses on the basis of similarity. For example, to one question, "How many years have you been doing field research?", some respondents typed in a number ("5"), others spelled it out in words ("five years"), others answered with mixed numerals and words ("5 years"), and still others gave partial years ("4 years and 11 months"). For each response, all partial years were rounded up to the next whole year, and all verbal or mixed numerical and verbal answers were changed to whole numbers only, creating a column of integers that could be more readily analyzed and compared with other responses.

Similar, though commonly nonnumerical, reclassification procedures were conducted for other open-ended questions, such as job title, field objectives, and type of data collected, as well as for various comments. For some open-ended questions, reclassification was difficult because of the wide range of responses. For these questions, certain responses are used in the body of this report to illustrate issues; the full list of responses is provided in appendix A. In addition, because some respondents gave more than one answer to open-ended questions, our reclassifications sometimes created more than one data point per respondent. For these questions, because we did not wish to discard any useful data, the tables in the next section distinguish between the number of respondents, $N$, and the number of individual responses, $R$, to a particular question. Where this notation is used, $N<R$.

Survey results and the discussion presented here do not represent all possible views on issues related to the use of mobilecomputing technology at the USGS but only the opinions of those individuals who chose to participate in the survey. Thus, the conclusions in this report are based on those responses alone and do not necessarily reflect any official USGS position. Because the collected data represent expressed, instead of revealed, participant perceptions and preferences, survey results cannot be used to solely gauge the potential success for mobile-computing technology at the USGS but should be considered only a starting point for further discussion on the opportunities and needs for mobilecomputing technology to support USGS fieldwork.

\section{Results}

The survey Web site was active for 2 months, and most responses were received within the first 2 weeks. After 2 months, responses were extracted from the database for analysis. During the survey, we received 144 responses from USGS scientists and technicians. Because few survey participants answered every question, the number of respondents to a question is typically less than 144; and because of the nested and contingent survey structure, not every respondent saw every question. In this report, we present survey results based on the number of participants who responded to each question, and remove nonrespondents, unless otherwise noted, where "respondents" refers to an adjusted percentage reflecting those survey participants who responded to that particular question. Unadjusted percentages and nonresponse rates are presented in appendix A. Apparent discrepancies between some of the percentages reported in the body of this report and those presented in appendix A reflect differences between these adjusted and unadjusted percentages.

We were unable to determine an overall response rate for the survey as a whole because we do not know how many USGS employees actually conduct fieldwork, whether a project chief answered as a representative for a group that conducts fieldwork, or how many USGS fieldworkers may have been unavailable during the survey period (for example, on annual leave or in the field). We note that survey participants were self-selecting and not a truly random sample of USGS fieldworkers. Thus, some bias may exist between those respondents who chose to complete the online survey and those who did not. We hope that future assessments will be conducted to further promote mobile-computing technology at the USGS.

One way to promote mobile-computing technology is to provide mechanisms for collaboration and communication between individuals who are already using it or are receptive to learning more about it. When asked, 75 survey respondents (52 percent) gave their name, telephone number, or both so that they could be contacted for further input on developing field tools. This information could be used to create a bureauwide network of technology-using field scientists and a clearinghouse of mobile-computing-technology strategies, scripts, and product-use ideas.

\section{Participant Demographics}

To provide some context for the survey results discussed in this report, we summarize the demographics of survey participants. Most participants are employed in the Western Region (68 percent), with fewer from the Central Region (19 percent) and the Eastern Region (12 percent), and some in no stated region ( 1 percent). In addition, most participants are from the Water Resources Discipline (WRD) (54 percent), fewer from the Biological Resources Discipline (22 percent), the Geology Discipline (14 percent), the Geography Discipline (10 percent), and the Geospatial Information Office (0 percent), and, again, some with no stated discipline (1 percent). A significant WRD presence was also observed in the distribution of participants' position titles, where 41 percent of participants were either hydrologists or hydrologic technicians (table 1). Without complete knowledge of the full range of USGS 
Table 1. Job titles of survey participants.

[IT, information technology. N, number of respondents to question]

\begin{tabular}{|c|c|}
\hline Job Title & $\begin{array}{c}\text { Response } \\
\text { rate } \\
\text { (percent) }\end{array}$ \\
\hline 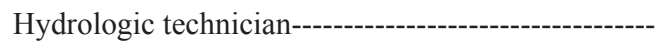 & 23 \\
\hline Hydrologist----------------. & 18 \\
\hline Geologist---------- & 11 \\
\hline 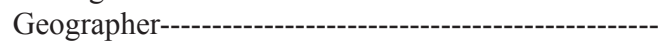 & 6 \\
\hline Physical scientis-------. & 6 \\
\hline Ecologist------------ & 5 \\
\hline 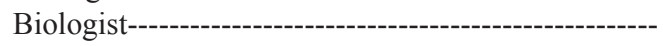 & 4 \\
\hline 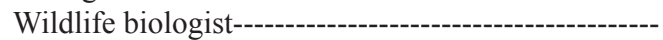 & 4 \\
\hline Fishery biologist-------------- & 3 \\
\hline 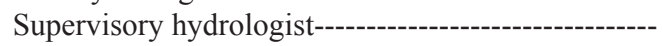 & 2 \\
\hline 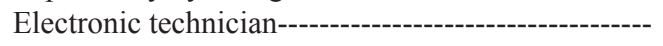 & 1 \\
\hline General biologist------------ & 1 \\
\hline 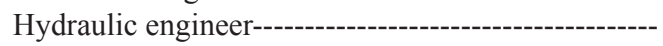 & 1 \\
\hline IT specialist------------------------------ & 1 \\
\hline Research scientist------------------------- & 1 \\
\hline Supervisory hydrologic technician------------------- & 1 \\
\hline Zoologist----------------------------- & 1 \\
\hline Assistant unit leader---------------- & 1 \\
\hline Biological science technician-------- & 1 \\
\hline Cartographer---------------------. & 1 \\
\hline Chemical oceanographer----------- & 1 \\
\hline 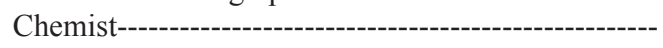 & 1 \\
\hline 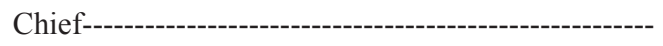 & 1 \\
\hline 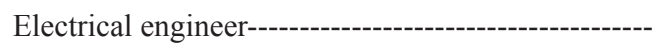 & 1 \\
\hline 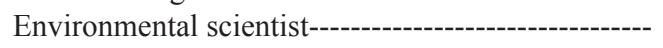 & 1 \\
\hline 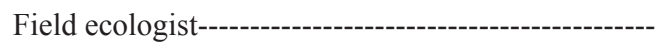 & 1 \\
\hline 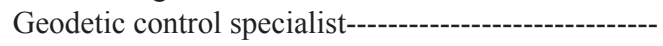 & 1 \\
\hline Geophysicist---------------------------------------------- & 1 \\
\hline Marine ecologist---- & 1 \\
\hline 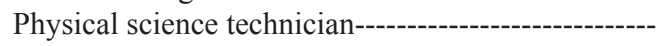 & 1 \\
\hline Remote-sensing scientist-------- & 1 \\
\hline 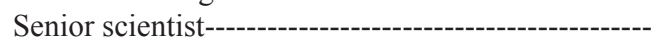 & 1 \\
\hline Social scientist---- & 1 \\
\hline
\end{tabular}

$N=143$
Table 2. Types of landscape for fieldwork by survey participants.

[N, number of respondents to question]

\begin{tabular}{|c|c|}
\hline $\begin{array}{l}\text { Landscape } \\
\text { type }\end{array}$ & $\begin{array}{c}\text { No. of } \\
\text { responses }\end{array}$ \\
\hline Various------- & 40 \\
\hline River------------------ & 24 \\
\hline Wetland --------------- & 18 \\
\hline Desert ------------ & 13 \\
\hline Estuary --------------- & 7 \\
\hline Forest------'-------- & 7 \\
\hline Riparian -------------- & 5 \\
\hline Polar ------------------ & 4 \\
\hline Arid---------- & 3 \\
\hline Grassland ------------ & 3 \\
\hline Mountains------------- & 3 \\
\hline Volcanic-------------- & 3 \\
\hline Lacustrine------------- & 2 \\
\hline (None given)--------- & 2 \\
\hline Urban----------------- & 2 \\
\hline Coastal zone ---------- & 1 \\
\hline Flood plain----------- & 1 \\
\hline Well area------------- & 1 \\
\hline
\end{tabular}

$N=139$

fieldworkers, we cannot state whether the predominance of WRD employees demonstrates an unrepresentative sample population for the survey. In fact, such a large percentage of USGS fieldwork may be performed by hydrologists or hydrologic technicians.

The distribution of years of field experience of survey participants $(N=141)$ is quite broad, ranging from 1 to 41 years, with a mean of 15.5 years (s.d., 9.5 years) and a median and mode of 15 years. A histogram of years of field experience shows a distribution of survey respondents (fig. 3 ) that is not significantly skewed toward either end of the spectrum, suggesting that the sample population, at least in terms of years of USGS fieldwork, may fairly represent all USGS fieldworkers. Figure 3 also shows spikes at 15, 20, 25, 30, and 35 years, suggesting that some respondents with many years of experi-

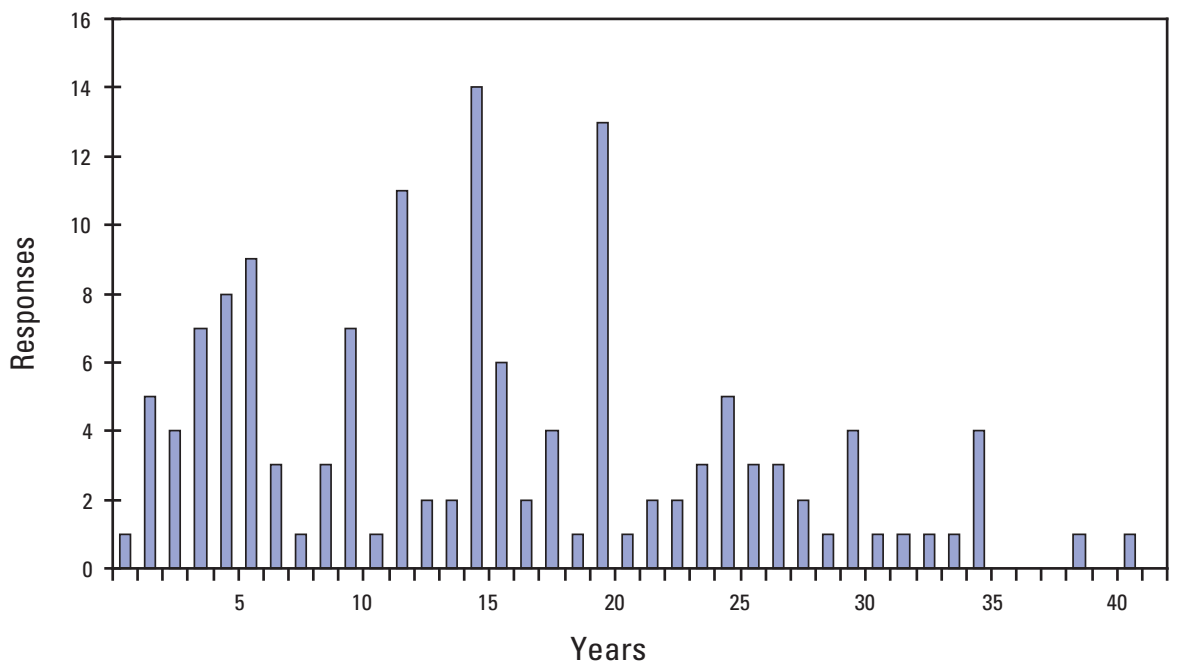

Figure 3. Histogram of respondents' numbers of years of field research. 
Table 3. Primary objectives for fieldwork by survey participants.

[GHT, Geographic Hash Table; GPS, Global Positioning System. N, number of respondents to question]

\section{Primary objective for fieldwork}

No. of responses

Water quality and (or) quantity monitoring --------------- 46

Data collection-general ------------------------------ 36

Geologic mapping ------------------------------------------ 14

Ecologic mapping ------------------------------- 7

Land-use/landcover mapping -------------------------- 7

Fish sampling ------------------------------- 5

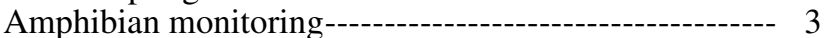

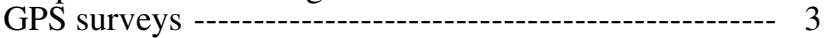

Vegetation mapping----------------------------------- 3

Question considered too vague, no answer given-------- 2

Bear monitoring --------------------------------------- 1

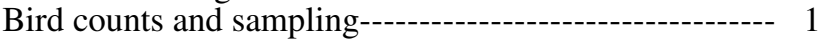

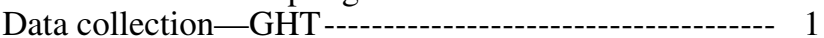

Data collection-meteorologic ------------------------- 1

Field verification of remote-sensing classifications ----- 1

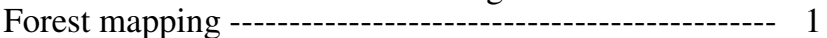

Geomorphic mapping --------------------------------- 1

Lava-flow monitoring------------------------------------- 1

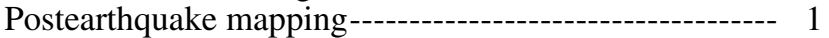

Soil sampling ---------------------------------------------- 1

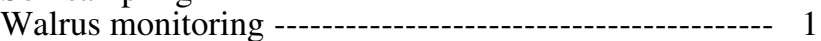

$N=137$

ence may have rounded their answers to the nearest 5-year increment.

To understand field conditions, we asked survey participants to answer an open-ended question on the types of landscape or environment in which they typically work while in the field. The purpose of this question was to understand field conditions and not to assess the demand for mobile-computing technology, because such demand will vary with the type of research. Similar responses were grouped into categories of our own design (table 2). If more than one distinct landscape type was mentioned (for example, "Mountains, deserts, forests, croplands, urban"), the response was coded as "Various." Results suggest that most survey participants conduct fieldwork in more than one type of landscape. The most common responses after "Various" were rivers and wetlands, possibly reflecting the many respondents who are WRD scientists.

\section{Fieldwork Goals, Technology, and Conditions}

One set of survey questions focused on the goals, procedures, supporting technology, and environmental conditions of fieldwork. Survey participants were first asked, in an openended question, to describe their primary fieldwork objectives. Similar responses were grouped into categories of our own design (table 3$)$. The large number of responses $(R=46)$ to questions related to "water-quality and (or) -quantity monitoring" reflects the high percentage of survey participation by WRD scientists. On the basis of subsequent responses, this type of fieldwork most likely consists of site sampling and data downloads, which could benefit from the use of PDAs. In hindsight, this question may have been too vague, because the second most common type of response included some generic comment on data collection. Furthermore, two respondents commented that the question itself was too vague, and gave no other response. Following these first two response types, the next set of responses all focused on some type of regional mapping, including geologic, hydrologic, biologic, and land use/landcover. Mobile-computing solutions that use tablet PCs would probably be more beneficial for this type of fieldwork, although such a decision should be on a case-by-case examination.

Survey participants were then asked to comment on their field activities. Nearly all respondents (99 percent) answered that they record observations, and 87 percent answered that they take samples. Nonetheless, the focus of their data-collection efforts varies considerably. Similar responses were grouped into categories of our own design (table 4). Again, observations and samples related to hydrologic issues were the most common responses. General environmental conditions of a study area were the most common recorded field observation, regardless of the type of research being conducted. We note also that here $N \neq R$, because some respondents gave more than one answer.

In addition to recording observations and taking samples, most respondents (59 percent) map environmental features while in the field (table 5). Sampling sites are the most commonly mapped features, followed by geologic and (or) geomorphic features. Most respondents stated that they sketch features directly into paper notebooks, on aerial photographs, on annotated GPS points, or on topographic-map sheets. Apparently, as we originally hypothesized, many of these fieldworkers may benefit from the use of mobile-computing technology to digitally map environmental features. As the USGS begins to develop computer applications and mobilecomputing technology specifically for field use, it will be important to determine exactly what types of feature are being sketched (for example, points, lines, or areas) and for what purpose.

We also compared the percentage of respondents who answered that they conduct mapping with the discipline in which they are employed (table 6). Results suggest that the percentage of respondents in the Geography and Biological Resources Disciplines who map environmental features does not differ significantly from the overall response rate of all the disciplines. The Geology Discipline may be somewhat overrepresented in the group of mappers, whereas WRD may be somewhat underrepresented. The large percentage of hydrologists and hydrologic technicians who participated in the survey explains much of this difference because they are less likely to conduct mapping.

To determine the breadth of mobile-computing-technology use in the USGS, we asked survey participants whether they use certain devices while in the field (table 7). Almost all respondents (98 percent) to this question use cameras, and most respondents (96 percent) claim to use digital cameras, either alone (93 percent) or in combination with film photography 
Table 4. Types of observation made and sample taken by survey participants.

[GPS, Global Positioning System. $N$, number of respondents to question; $R$, number of individual responses to question]

\begin{tabular}{|c|c|c|c|}
\hline Field observation & $\begin{array}{l}\text { No. of } \\
\text { responses }\end{array}$ & Type of sample & $\begin{array}{c}\text { No. of } \\
\text { responses }\end{array}$ \\
\hline 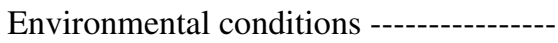 & 55 & Water-quality data----------- & 32 \\
\hline Water-quality data----- & 54 & Water------------------------- & 29 \\
\hline Channel and control conditions -------- & 33 & Sediment/soil----------------- & 25 \\
\hline Location ---------------------- & 27 & Animal ---------------------- & 16 \\
\hline Habitat/vegetation characteristics ------- & 25 & Rocks ----------------------- & 12 \\
\hline Animal behavior/characteristics -------- & 17 & Plants-------------------------- & 9 \\
\hline 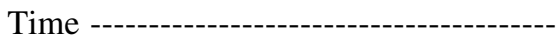 & 16 & Site characteristics----------- & 6 \\
\hline Bedrock structures/ rock types -------- & 13 & Suspended sediment--------- & 5 \\
\hline 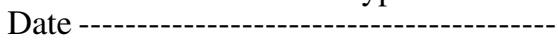 & 13 & GPS data------------------- & 4 \\
\hline Quality-assurance data------------------ & 11 & Animal history ---------------- & 3 \\
\hline Landcover type/condition --- & 8 & 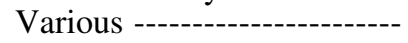 & 3 \\
\hline Sediment characteristics ---------------- & 7 & Schedule 19 QW------------- & 1 \\
\hline Landform -- & 4 & Unknown --------------- & 1 \\
\hline Photograph --------------------------------- & 4 & & \\
\hline 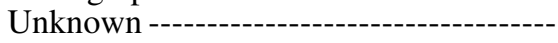 & 2 & & \\
\hline Archeologic remains ---------------- & 1 & & \\
\hline Field datalogger parameters --- & 1 & & \\
\hline Human behavior & 1 & & \\
\hline 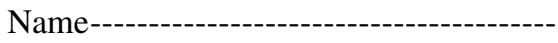 & 1 & & \\
\hline Ocean conditions - & 1 & & \\
\hline Seismic/sonar data--- & 1 & & \\
\hline Sketches --1- & 1 & & \\
\hline Snow characteristics -- & 1 & & \\
\hline
\end{tabular}

$N=133, R=297$

$N=123, R=146$

Table 5. Environmental features mapped in the field by survey participants.

[GPS, Global Positioning System. $N$, number of respondents to question; $R$, number of individual responses to question]

\begin{tabular}{|c|c|c|c|}
\hline What do you map? & $\begin{array}{l}\text { No. of } \\
\text { responses }\end{array}$ & How do you do map features? & $\begin{array}{c}\text { No. of } \\
\text { responses }\end{array}$ \\
\hline 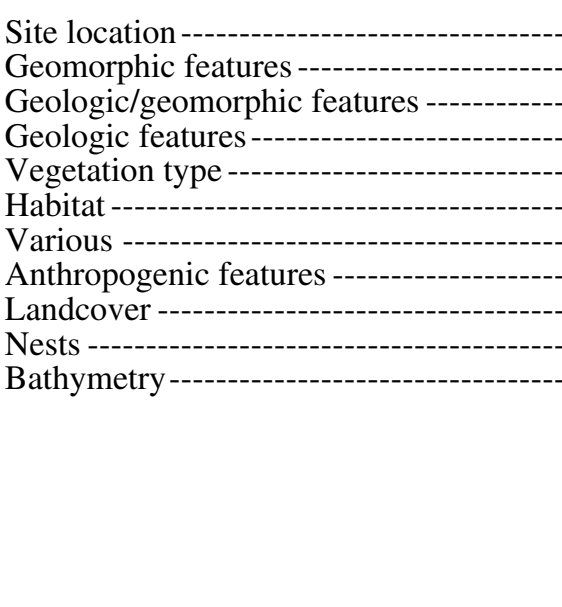 & $\begin{array}{rr}- & 28 \\
- & 11 \\
- & 8 \\
- & 6 \\
- & 6 \\
-\quad 5 \\
-\quad 5 \\
-\quad 3 \\
-\quad 3 \\
-\quad 2\end{array}$ & 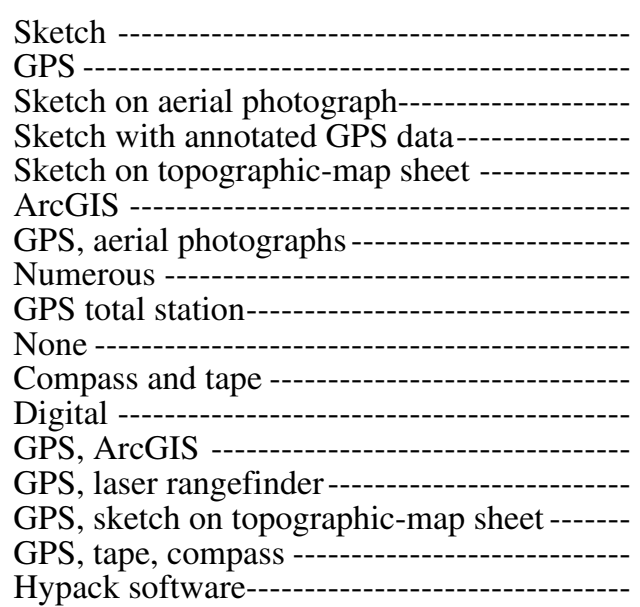 & $\begin{array}{r}18 \\
16 \\
9 \\
7 \\
6 \\
5 \\
4 \\
4 \\
2 \\
2 \\
1 \\
1 \\
1 \\
1 \\
1 \\
1 \\
1\end{array}$ \\
\hline
\end{tabular}


Table 6. Mapping of environmental features in the field by survey participants, by USGS discipline.

$[\mathrm{N}$, number of respondents to question]

\begin{tabular}{llccrr}
\hline $\begin{array}{c}\text { Response rate } \\
\text { (percent) }\end{array}$ & Geography & Geology & $\begin{array}{c}\text { Biological } \\
\text { Resources }\end{array}$ & $\begin{array}{c}\text { Water } \\
\text { Resources }\end{array}$ & $\boldsymbol{N}$ \\
\hline $\begin{array}{l}\text { Those who map features --------- } \\
\text { Overall survey response-------- }\end{array}$ & 11 & 21 & 23 & 45 & 82 \\
& & 14 & 22 & 54 & 143 \\
\hline
\end{tabular}

Table 7. Uses of mobile-computing technology in the field by survey participants.

[GPS, Global Positioning System; PC, personal computer; PDA, personal digital assistant]

\begin{tabular}{cc}
\hline $\begin{array}{c}\text { Respondents } \\
\text { who say they: }\end{array}$ & $\begin{array}{c}\text { Response } \\
\text { rate } \\
\text { (percent) }\end{array}$ \\
\hline Take photographs ----------- & 98 \\
Use digital camera---------- & 96 \\
Use a GPS receiver--------- & 88 \\
Use a paper map ----------- & 78 \\
Use a field computer ------- & 76 \\
Use a PDA -------------- & 34 \\
Use a tablet PC ---------- & 12 \\
\hline
\end{tabular}

( 2 percent). ${ }^{1}$ The second-most common device mentioned by survey participants ( 88 percent) is a GPS receiver. When asked to describe how they use GPS receivers in the field, respondents commonly answered for "Location/navigation," although many respondents misunderstood the question and instead listed the type of GPS receiver that they use (see app. A).

Although significant percentages of respondents use such devices as GPS receivers ( 88 percent) and laptop computers (76 percent) in the field, the use of paper maps remains quite prevalent among survey participants (78 percent). To many of the open-ended questions (see app. A), many survey participants answered that they gain much efficiency by combining lightweight, "low tech" paper versions of spatial information

\footnotetext{
${ }^{1}$ Owing to rounding, not all the percentages presented herein sum to 100 percent.
}

Table 8. Type, purpose, and scale of maps used in the field by survey participants.

[DRG, digital raster graphics; DOQ, digital orthophoto quadrangle; GPS, Global Positioning System; NOAA, National Oceanic and Atmospheric Administration; UTM, universal transverse mercator. N, number of respondents to question; R, number of individual responses to question]

\begin{tabular}{|c|c|c|c|c|c|}
\hline Aerial photography/DOQ--------- & 24 & Navigation ---------------------- & 28 & Various------------- & 26 \\
\hline Roadmaps ------------------------- & 15 & Sampling-site location---------- & 14 & 1:100,000 --------- & 6 \\
\hline Self-made GIS map------------- & 8 & Plotting------- & 5 & 1:10,000--------- & 3 \\
\hline Remotely sensed imagery---------- & 7 & Ground-truthing-------------- & 3 & 1:15,000--------- & 2 \\
\hline NOAA chart---------------- & 5 & Visualization ------------------- & 3 & 1:12,000---------- & 2 \\
\hline Geologic maps ------------------- & 5 & Notation----------------------- & 3 & 1:80,000--------- & 1 \\
\hline Other Federal agencies ----------- & 5 & Computer backup ----------- & 2 & 1:40,000-------- & 1 \\
\hline Paper map --- & 3 & Flight planning ------------ & 2 & $1: 30,000$ & 1 \\
\hline Hand-drawn map ----------------- & 2 & Stream-channel tracking ------- & 2 & 1:6,000 ---------- & 1 \\
\hline Commercial GPS map ----------- & 1 & Locate datum -------------- & 1 & Other --------- & 1 \\
\hline Self-made image map ------------ & 1 & Vegetation mapping ------------ & 1 & & \\
\hline Navigation software --- & 1 & Georeferencing---------- & 1 & & \\
\hline UTM reference grid -------------- & 1 & Data analysis --------------- & 1 & & \\
\hline
\end{tabular}


Table 9. Primary uses of mobile-computing technology by survey participants.

[GPS, Global Positioning System; PDA, personal digital assistant. $N$, number of respondents to question; $R$, number of individual responses to question]

\begin{tabular}{|c|c|c|c|}
\hline Use of PDA & $\begin{array}{l}\text { No. of } \\
\text { responses }\end{array}$ & Use of tablet PC & $\begin{array}{c}\text { No. of } \\
\text { responses }\end{array}$ \\
\hline Collect data--------------------------- & 38 & 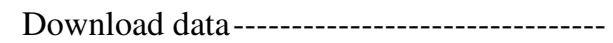 & 7 \\
\hline Use GPS ------------------------------- & 9 & 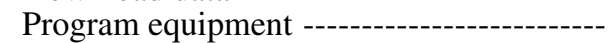 & 5 \\
\hline Look up contact information -------- & 6 & 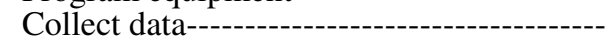 & 4 \\
\hline Maintain schedule/calendar----------- & 5 & Graph data-------------------------------------- & 2 \\
\hline Download data --------------------- & 4 & Use GPS ------------------------------------- & 2 \\
\hline Access background data ------------- & 3 & Map vegetation ----------------------------- & 1 \\
\hline Navigation--------------------------- & 2 & Map human-impact features--------------- & 1 \\
\hline \multirow[t]{2}{*}{ 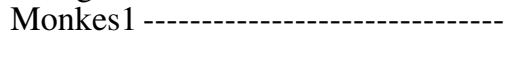 } & 1 & Provide information for field ID ---------- & 1 \\
\hline & & Same as PDA but with bigger files -------- & 1 \\
\hline
\end{tabular}

$N=48, R=68$

with more advanced techniques to perform different aspects of fieldwork. Respondents were asked followup questions on map type, purpose, and scale in their fieldwork (table 8): the most common type is a topographic map, followed by aerial photographs; the most common purpose is for locating study sites and for general navigation; and the most common scale is $1: 24,000$, that of USGS topographic-quadrangle maps.

Although GPS receivers and laptop computers have become almost commonplace in USGS fieldwork, other devices have not caught on to the same extent. Only 34 percent of respondents use PDAs in the field, and only 12 percent use tablet PCs (table 7). Primary uses of PDAs and tablet PCs include data collection and GPS data acquisition (table 9). Results suggest that survey participants are using tablet PCs to download data and to program field equipment, as if they are simply larger versions of PDAs, without tapping into the unique functionality of the tablet $\mathrm{PC}$, such as digital feature mapping or voice recognition. Despite the low rates of PDA and tablet-PC use (table 7), those who do use them apparently do so at a fairly high level of sophistication because more than 24 percent of users of those devices have created specialized scripts or software programs for them. Typical scripts include checking data accuracy, field calculations, collecting and processing water quality and quantity data, linking field observations to databases, processing GPS data, and miscellaneous data-collection forms (see app. A).

After responding on the purpose and type of mobilecomputing technology used in fieldwork, survey participants were asked to comment on fieldwork conditions (table 10). Information from this set of responses could help determine the overall demand for and type of mobile-computing technology at the USGS. For example, if many USGS scientists spend significant time in the field, the USGS could allocate bureauwide resources to promote mobile-computing technology. In this series of scripted questions, survey participants were asked to comment on the average length of a field trip,
$N=16, R=24$ the number of days per year spent in the field, and the size of field crews. Results for the average time per year spent in the field (table 10) indicate more than 1 week for 95 percent and at least 1 month for 68 percent of survey participants. Results for the average length of an individual field investigation (table 10) indicate 1 week for 44 percent and 1 day for 22 percent of survey participants. Therefore, approximately two-thirds of field investigations are 1 week or less in duration.

Sizes of field crews vary among survey participants; 28 percent of respondents stated that they go to the field alone. For these individuals, backpack space and weight are significant concerns, and so mobile-computing technology, such as PDAs or tablet PCs, could minimize the number of items, such as hardcopy maps, compasses, and notebooks, that a researcher needs to transport to the field. At the other end of the spectrum, 38 percent of respondents stated that their field crews consist of three or more people. For these larger field crews, mobile-computing technology can also be helpful by streamlining logistics and standardizing data collection and processing with common software platforms and hardware tools.

To examine issues relating to equipment weight and battery life of mobile-computing technology, survey participants were asked to comment on how far they travel in the field. A total of 79 percent of respondents to this question $(N=142)$ stated that they travel on foot away from a vehicle for fieldwork. An open-ended followup question asked how far they typically travel away from the field vehicle. We first standardized the 110 responses to this question (for example, "two miles" and "a mile or two" became " 2 miles") and then created categories of (1) up to $1 / 2 \mathrm{mi}$, (2) from $1 / 2$ to $2 \mathrm{mi}$, (3) greater than $2 \mathrm{mi}$, and (4) various, to approximate the willingness of an individual to carry mobile-computing technology and (or) walk back to a vehicle for additional batteries. (Many laptop computers, in addition to being heavy, have batteries that last only about 4 hours.) We assumed that willingness to retrieve batteries was high for distances up to $1 / 2$ mi, moderate for $1 / 2$ to 
Table 10. Aspects of fieldwork conditions reported by survey participants.

\begin{tabular}{lc}
\hline $\begin{array}{c}\text { Average time } \\
\text { per year } \\
\text { spent in the field }\end{array}$ & $\begin{array}{c}\text { Response } \\
\text { rate } \\
\text { (percent) }\end{array}$ \\
\hline$<1$ week & \\
$<1$ month-------------------------- & 4 \\
$1-3$ months --------------------- & 27 \\
$3-6$ months --------------------- & 40 \\
$>6$ months -------------------- & 23 \\
No response ----------------- & 1 \\
\hline
\end{tabular}

\section{Average length of an individual field investigation}

\begin{tabular}{|c|c|}
\hline 1 day & 22 \\
\hline 1 week- & 44 \\
\hline 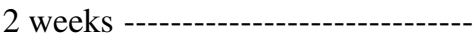 & 10 \\
\hline 1 month ----------------------------- & 6 \\
\hline 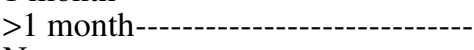 & 13 \\
\hline No response - & 6 \\
\hline
\end{tabular}

\section{Size of field crew, in addition to the respondent}

\section{No one else \\ One other person- \\ Two other people \\ Three other people- \\ No response \\ Distance traveled \\ from vehicle \\ for fieldwo1k} 28

Four or more other people --.---.--

\begin{tabular}{lr}
\hline Up to $1 / 2 \mathrm{mi}----------------------$ & 38 \\
From $1 / 2$ to $2 \mathrm{mi}----------------$ & 32 \\
From 2 to $5 \mathrm{mi}$------------------ & 25 \\
Various----------------------- & 4 \\
No response -------------------- & 1
\end{tabular}

$2 \mathrm{mi}$, and low for more than $2 \mathrm{mi}$ from a field vehicle. Most respondents ( 57 percent) travel more than $1 / 2 \mathrm{mi}$ from a vehicle during fieldwork (table 10). These considerations are important when developing hardware and (or) software solutions because of the need to address equipment weight and battery life.

Along with similar concerns about mobile-computing-technology development and implementation, survey participants were also asked how rugged their field equipment needed to be: 55 percent of respondents to this ques- tion answered that equipment needed to be waterproof or environmentally sealed, and 45 percent would be using this equipment in controlled environments and so would not need ruggedized equipment or take special precautions (see app. A, question 11).

\section{Postfieldwork Data Processing and Analysis}

One of the primary strengths of mobile-computing technology is its ability to minimize transcription time and errors in postfieldwork data processing and analysis because scientists are able to enter data directly into digital databases while in the field. To better understand the need for this facility, survey participants were asked a series of questions about current postfieldwork data processing and analysis in their offices. A total of 93 percent of respondents to this question answered that they enter collected field data into their office computers, of which 70 percent enter their own data and 23 percent of participants have someone else do it for them (see app. A, question 16). These results suggest that most individuals enter their own collected field data into their office computers, except in the Biological Resources Discipline, where 15 of 25 respondents answered that someone else enters their data for them (see app. A, question 16). In addition to data input, 27 percent of respondents to this question also spend office time recording field observations or mapping features manually on a paper map or photograph (see app. A, question 17).

The length of time reported for postfieldwork data processing by survey participants varies considerably (table 11), from 1 day (31 percent) to greater than 1 month (11 percent); the most common responses were 1 day (31 percent) and 1 week (32 percent). To evaluate the potential impact of postfieldwork data processing on USGS financial resources, we calculated the amount, in terms of salary dollars per year, that could be spent on this activity for the 111 respondents to this question. For general estimates, we multiplied the hourly rates of different grade-step (GS) levels for the length of time that respondents answered it took them to process field data. For example, 35 respondents stated that they took 1 day to process field data, 35 that they took 1 week, and 14 that they took 2 weeks (table 11). For respondents who answered "greater than 1 month," we used 1 month as a conservative assessment of the time spent by these individuals. For this calculation, we used hourly rates from the U.S. Office of Personnel Management's 2005 Salary and Wages general locality pay tables (URL http://www.opm.gov/oca/05tables/ indexGS.asp); results for the various time periods are listed in table 12. We assume homogeneous blocks of employees and not a range of GS levels, although in reality a mixed group of GS levels exists across the bureau. Therefore, the range of GS levels from 7 to 15 should be the main focus for further discussion and not the specific values in each column. With this cautionary note, general estimates of the salary paid to conduct postfieldwork data processing range from $\$ 105,000$ to $\$ 309,000$ per year for the 111 respondents to this question. This range is certainly much greater when 
Table 11. Estimated time worked by, and salary paid to, survey participants to conduct postfieldwork data processing.

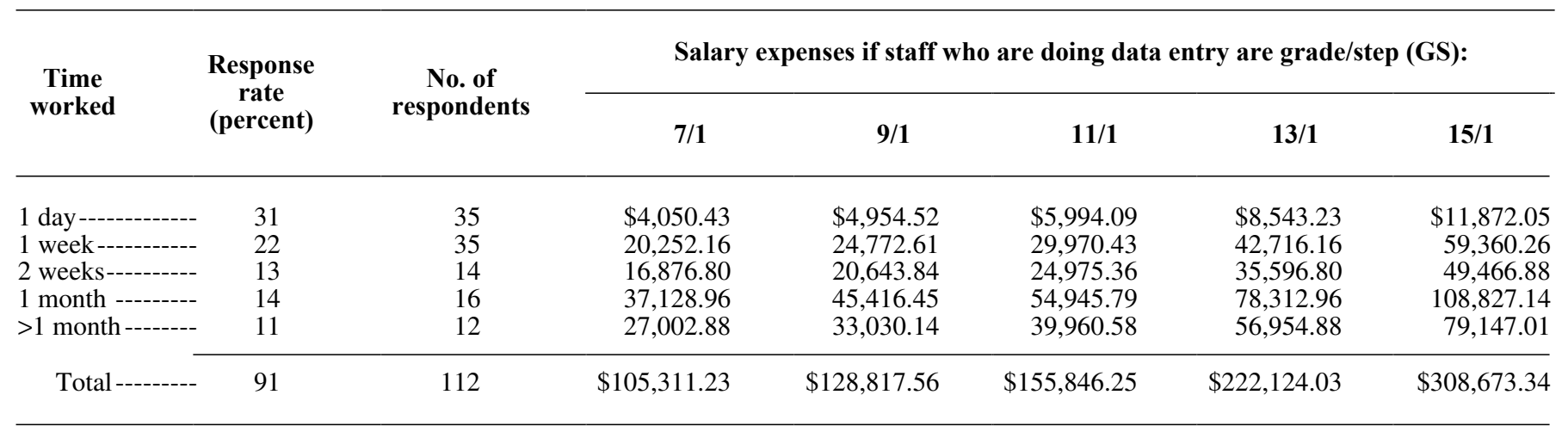

the full spectrum of USGS fieldworkers is included in the calculations.

We note that the phrasing of the original question focused on the actual time spent entering field data, although some respondents may have interpreted this question to be asking how long it took them to get around to actually doing it, or the additional time for data-quality assurance and control. Therefore, our general estimates of the salary paid to conduct postfieldwork data processing should, again, be considered only starting points for additional discussions, not as an endorsement for data-collection standards or mandated use of mobile-computing technology. Survey results indicate that USGS research is quite diverse and that the development of data-collection standards or mandated use of mobile-com- puting technology will require additional study and bureauwide discussion. Nonetheless, it is clear that field-data entry, both into databases and on paper maps, is a time-intensive task for many USGS scientists and that properly designed mobile-computing technology may be able to reduce this time for individual researchers or larger research groups composed of multiple fieldworkers with similar data-collection methods. These preliminary estimates of the salary paid to conduct postfieldwork data processing suggest that the USGS could examine enterprise solutions to help fieldworkers use mobile-computing technology, through both training opportunities and a bureau-level technical team.

After USGS scientists enter their new field data into their office computers, many will then analyze those data

Table 12. Salary table for Federal employees used to estimate salary paid to survey participants to conduct postfieldwork data processing.

[Hourly rates (from U.S. Office of Personnel Management 2005 Salary Tables and Wages, URL http://www.opm.gov/oca/05tables/indexGS.asp) reflect basic salary at step 1 for each grade, exclusive of overtime or additional locality-pay rates; values in other columns are hourly rates multiplied by the number of hours in each time period]

\begin{tabular}{cccccr}
\hline $\begin{array}{c}\text { Grade/step } \\
\text { (GS) }\end{array}$ & $\begin{array}{c}\text { Hourly } \\
\text { rate }\end{array}$ & $\begin{array}{c}\text { 1-day wages } \\
\text { (8 hours) }\end{array}$ & $\begin{array}{c}\text { 1-week wages } \\
\text { (40 hours) }\end{array}$ & $\begin{array}{c}\text { 2-week wages } \\
\text { (80 hours) }\end{array}$ & $\begin{array}{c}\text { 1-month wages } \\
\text { (160 hours) }\end{array}$ \\
\hline & & & & & \\
$1 / 1$ & $\$ 7.67$ & $\$ 61.36$ & $\$ 306.80$ & $\$ 613.60$ & $\$ 1,227.20$ \\
$2 / 1$ & 8.63 & 69.04 & 345.20 & 690.40 & $1,380.80$ \\
$3 / 1$ & 9.41 & 75.28 & 376.40 & 752.80 & $1,505.60$ \\
$4 / 1$ & 10.57 & 84.56 & 422.80 & 845.60 & $1,691.20$ \\
$5 / 1$ & 11.82 & 94.56 & 472.80 & 945.60 & $1,891.20$ \\
$6 / 1$ & 13.18 & 105.44 & 527.20 & $1,054.40$ & $2,108.80$ \\
$7 / 1$ & 14.65 & 117.20 & 586.00 & $1,172.00$ & $2,344.00$ \\
$8 / 1$ & 16.22 & 129.76 & 648.80 & $1,297.60$ & $2,595.20$ \\
$9 / 1$ & 17.92 & 143.36 & 716.80 & $1,433.60$ & $2,867.20$ \\
$10 / 1$ & 19.73 & 157.84 & 789.20 & $1,578.40$ & $3,156.80$ \\
$11 / 1$ & 21.68 & 173.44 & 867.20 & $1,734.40$ & $3,468.80$ \\
$12 / 1$ & 25.98 & 207.84 & $1,039.20$ & $2,078.40$ & $4,156.80$ \\
$13 / 1$ & 30.90 & 247.20 & $1,236.00$ & $2,472.00$ & $4,944.00$ \\
$14 / 1$ & 36.51 & 292.08 & $1,460.40$ & $2,920.80$ & $5,841.60$ \\
$15 / 1$ & 42.94 & 343.52 & $1,717.60$ & $3,435.20$ & $6,870.40$ \\
& & & & & \\
\hline
\end{tabular}


Table 13. GIS usage by survey participants.

[ $N$, number of respondents to question; $R$, number of individual responses to question]

\begin{tabular}{lc}
\hline Category of use & $\begin{array}{c}\text { No. of } \\
\text { responses }\end{array}$ \\
\hline Mapping/illustration----------- & 49 \\
Spatial analysis ---------------- & 39 \\
Site selection ---------------- & 19 \\
Database management -------- & 12 \\
Spatial modeling-------------- & 6 \\
Location verification --------- & 3 \\
Various ------------------------ & 2 \\
Image processing ------------ & 1 \\
& \\
\hline
\end{tabular}

$N=87, R=131$

using software tools on their desktop PCs. A series of questions asked about these software tools to determine whether mobile-computing technology could support their use in field efforts. With their ability to manage and analyze spatial data, GISes have become powerful tools for researchers. Survey results indicate that 68 percent of respondents currently use a GIS in their research (see app. A, question 18). In an open-ended followup question, respondents could list one or more types of GIS system. Of the 90 respondents to this question, 85 stated that they use some sort of ESRI product, such as ArcGIS or ArcPad (see app. A, question 18a). Of the 143 responses $(R=143), 111$ (78 percent) mentioned an ESRI product. Therefore, the USGS should consider compatibility with ESRI data frameworks and software in future efforts to develop mobile-computing-technology solutions for fieldworkers.

Respondents who answered that they use a GIS were asked to comment, in an open-ended question, on how they used a GIS in their research. Again, many of the 87 respondents to this question $(N=87)$ chose to give more than one answer, bringing the total number of responses to 131 $(R=131)$. Similar responses were grouped into categories of our own design (table 13). The most common response to GIS use was for general mapping and illustration (49 responses), followed by spatial analysis (39 responses) and site selection (19 responses). With a PDA's ability to run ArcPad, a limited GIS package, and a tablet PC's ability to support full ArcGIS functionality, individual researchers should determine whether these GIS uses would be advantageous in the field. For example, the ability of a tablet PC to illustrate the landscape may be useful to researchers for creating adaptive or dynamic sampling designs, interacting with their field crews, or communicating research results to customers, such as land managers. Field-based spatial analysis may be useful for decisionmaking about ongoing events, such as disaster preparedness or emergency-response efforts. Finally, mobile-computing technology can address the use of a GIS for database management because the technology can
Table 14. Types of remotely sensed imagery used by survey participants.

[ASTER, Advanced Spaceborne Thermal Emission and Reflection Radiometer; GOES, Geostationary Operational Environmental Satellite; InSAR, interferometric synthetic-aperture radar; MASTER, MODIS/ASTER airborne simulator; SPOT, Satellite Pour l'Observation de la Terre (French for "Earth-observation satellite"). N/A, not applicable. $N$, number of respondents to question; $R$, number of individual responses to question]

\begin{tabular}{|c|c|}
\hline $\begin{array}{l}\text { Type of } \\
\text { remotely sensed imagery }\end{array}$ & $\begin{array}{l}\text { No. of } \\
\text { responses }\end{array}$ \\
\hline 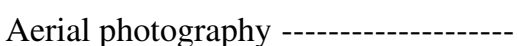 & 15 \\
\hline 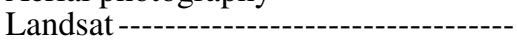 & 15 \\
\hline Digital orthophotoquad----- & 13 \\
\hline Lidar --------------------------------------- & 11 \\
\hline 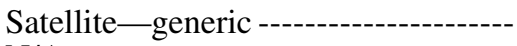 & 11 \\
\hline 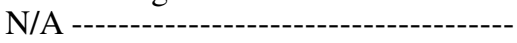 & 6 \\
\hline 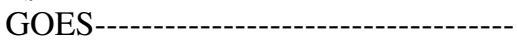 & 4 \\
\hline InSAR ----- & 4 \\
\hline MASTER -- & 4 \\
\hline 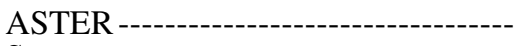 & 3 \\
\hline Stage-------- & 3 \\
\hline Hyperspectral--------------------------- & 2 \\
\hline 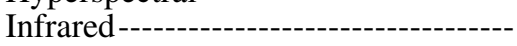 & 2 \\
\hline Quickbird ----------------------------- & 2 \\
\hline 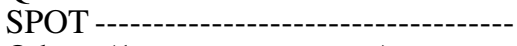 & 2 \\
\hline Others (1 response per type) ---------- & 19 \\
\hline
\end{tabular}

be used to instantly process data digitally as they are collected in the field.

Another useful tool for researchers is remotely sensed imagery. A total of 44 percent of respondents answered that

Table 15. Uses of remotely sensed imagery by survey participants.

[ $N$, number of respondents to question; $R$, number of individual responses to question]

\begin{tabular}{cc}
\hline Category of use & $\begin{array}{c}\text { No. of } \\
\text { responses }\end{array}$
\end{tabular}

Navigation/orientation ---------- 12

Hydrologic studies ------------- 9

Landcover mapping ------------ 9

Geologic mapping-------------- 7

Mapping/illustration ------------ 6

Study design --------------------- 4

Animal-habitat studies ---------- 3

Vegetation mapping------------- 2

Annual data report---------------- 1

Change detection ---------------- 1

Elevation models ----------------- 1

Ground-truthing ------------------ 1

Modeling -------------------------- 1

Multiband classification -------- 1

$N=55, R=58$ 
Table 16. Uses of geospatial datasets by survey participants.

[All values in percent]

\begin{tabular}{|c|c|c|c|c|c|c|c|c|c|c|c|c|}
\hline Data format & $\begin{array}{l}\text { Topo- } \\
\text { graphic } \\
\text { map }\end{array}$ & $\begin{array}{l}\text { Aerial } \\
\text { photog- } \\
\text { raphy }\end{array}$ & $\begin{array}{c}\text { Eleva- } \\
\text { tion }\end{array}$ & $\begin{array}{c}\text { Bathym- } \\
\text { etry }\end{array}$ & $\begin{array}{c}\text { Land } \\
\text { use }\end{array}$ & $\begin{array}{l}\text { Land- } \\
\text { cover }\end{array}$ & $\begin{array}{c}\text { Geol- } \\
\text { ogy }\end{array}$ & Soils & $\begin{array}{c}\text { Hydrol- } \\
\text { ogy }\end{array}$ & Roads & $\begin{array}{c}\text { Struc- } \\
\text { tures }\end{array}$ & $\begin{array}{l}\text { Geo- } \\
\text { graphic } \\
\text { names }\end{array}$ \\
\hline 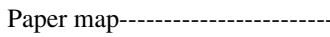 & 51 & 30 & 28 & 11 & 14 & 13 & 17 & 11 & 21 & 44 & 26 & 31 \\
\hline Digital format ------- & 28 & 32 & 29 & 11 & 18 & 19 & 17 & 15 & 16 & 27 & 13 & 19 \\
\hline Would use if available---------- & 6 & 14 & 12 & 8 & 14 & 13 & 14 & 14 & 14 & 9 & 11 & 10 \\
\hline Don't use -- & 9 & 14 & 15 & 31 & 22 & 24 & 25 & 30 & 20 & 6 & 16 & 13 \\
\hline No response -- & 6 & 10 & 16 & 40 & 32 & 32 & 27 & 30 & 29 & 15 & 34 & 27 \\
\hline $\begin{array}{l}\text { Either paper map, digital } \\
\text { format, or would use if } \\
\text { available. }\end{array}$ & (86) & (76) & (70) & (30) & (46) & (45) & (48) & $(40)$ & (51) & (80) & (50) & (60) \\
\hline
\end{tabular}

they use remotely sensed imagery in their research. The types and sources of remotely sensed imagery used by respondents vary greatly, although the most common types are aerial photographs, Landsat images, and digital orthophotoquads (table 14).

As in the previous questions about GIS usage, respondents who answered that they use remotely sensed imagery were asked to comment on how they use these data. Similar responses were grouped into categories of our own design (table 15). The most common response was "Navigation/orientation"; use for some type of mapping - whether landcover, geologic, or vegetation - was also a common response. Both PDAs and tablet PCs are capable of running GIS software with linked GPS receivers, allowing users to digitally create high-resolution GIS polygons in the field, such as wetland delineation or geologic boundaries, while also accessing remotely sensed imagery. Mobile-computing technology may increase the accuracy and precision of GIS mapping efforts and reduce the amount of data translation back in the office.

In addition to hardware and software, certain geospatial datasets are needed by researchers, and mobile-computing technology may allow researchers to use these data in the field. The proliferation of mobile-computing technology may increase the demand for certain data types as this facility becomes more widely available. Survey participants were asked to comment on their usage of a range of data types and formats (table 16). For 12 different data types, respondents chose one of the following options: paper map, digital format, would use if available, don't use, or no response (the default answer); they were also given the opportunity to identify other data types not mentioned here. As an aside, many respondents to this followup question answered that "Both paper map and digital format" would also have been a beneficial choice. To reflect the current and potential demand for certain data types if mobile-computing technology was more accessible, we present the total percentage of respondents who stated that they currently use paper maps or digital data or would use them if they were available.

Survey results suggest that the data types most sought after by respondents, regardless of format, are topographic maps ( 86 percent), roads ( 80 percent), aerial photographs (76 percent), and elevation data (70 percent); fewer respondents stated the need for bathymetric (30 percent) or soil (40 percent) data. Between these two extremes is a group of data types that about half of respondents believed to be useful, including landcover (45 percent), land use (46 percent), geology (48 percent), structures (50 percent), hydrology (51 percent), and geographic names (60 percent).

On the basis of responses in the category "Would use if available," the important areas for greater bureauwide access are aerial photographs, land use, geology, hydrology, and soils (each identified by approximately 14 percent of respondents). It is unclear whether "available" here meant actually available, affordably available, or feasibly available in the sense that it could be readily integrated with other data types and formats. In addition to the data types mentioned in the survey, respondents answered that other data types were important and listed them in an open-ended followup question: Advanced Spaceborne Thermal Emission and Reflection Radiometer (ASTER) imagery to identify rock types and alluvium sources, cultural features, streamflow data, GPS latitude/longitude waypoints, engineered structures (for example, dams), hazard maps, historical land use/disturbances, land ownership, National Oceanic and Atmospheric Administration (NOAA) charts, aviation maps, and weather data (including tide and wave heights).

In addition to the descriptive summaries of responses presented in this report, we also conducted statistical analyses to compare various sets of survey responses. We first developed a correlation matrix between certain field activities and the use of specific technologies to better understand possible synergies or interactions between the two categories (table 17). Values in the correlation matrix range from -1 to 1 , where values closer to 1 suggest that users are more inclined to use a specific technology, values closer to -1 suggest that users are less inclined to use a specific technology, and values close to 0 suggest little correlation, either positive or negative, between the two field activities or specific technologies on the axes of the matrix. For example, according to table 17 , there is a strong, positive correlation (0.504) between the use of PDAs and the creation of specialized scripts for PDAs, indicating that users of PDAs are also more inclined to create their own PDA scripts. 
Table 17. Correlation matrix between field activities and use of specific technologies.

\begin{tabular}{|c|c|c|c|c|c|c|c|c|c|c|c|}
\hline & $\begin{array}{c}\text { Collect } \\
\text { samples? }\end{array}$ & $\begin{array}{c}\text { Record } \\
\text { field } \\
\text { observations? }\end{array}$ & $\begin{array}{c}\text { Map } \\
\text { features? }\end{array}$ & $\begin{array}{c}\text { Use } \\
\text { a GPS? }\end{array}$ & $\begin{array}{l}\text { Use } \\
\text { paper } \\
\text { maps? }\end{array}$ & $\begin{array}{c}\text { Use } \\
\text { a PDA? }\end{array}$ & $\begin{array}{l}\text { Use } \\
\text { a tablet } \\
\text { PC? }\end{array}$ & $\begin{array}{l}\text { Developed } \\
\text { scripts? }\end{array}$ & $\begin{array}{c}\text { Use } \\
\text { a laptop } \\
\text { computer? }\end{array}$ & $\begin{array}{l}\text { Use } \\
\text { a GIS? }\end{array}$ & $\begin{array}{c}\text { Use } \\
\text { remotely } \\
\text { sensed } \\
\text { imagery? }\end{array}$ \\
\hline $\begin{array}{c}\text { Collect } \\
\text { samples? }\end{array}$ & 1.000 & & & & & & & & & & \\
\hline $\begin{array}{c}\text { Record } \\
\text { field } \\
\text { observations? }\end{array}$ & 0.285 & 1.000 & & & & & & & & & \\
\hline $\begin{array}{c}\text { Map } \\
\text { features? }\end{array}$ & 0.038 & 0.124 & 1.000 & & & & & & & & \\
\hline $\begin{array}{c}\text { Use } \\
\text { a GPS? }\end{array}$ & -0.014 & -0.035 & 0.206 & 1.000 & & & & & & & \\
\hline $\begin{array}{l}\text { Use } \\
\text { paper } \\
\text { maps? }\end{array}$ & -0.030 & 0.194 & 0.233 & 0.069 & 1.000 & & & & & & \\
\hline $\begin{array}{l}\text { Use } \\
\text { a tablet } \\
\text { PC? }\end{array}$ & 0.054 & 0.042 & 0.157 & -0.054 & -0.069 & 0.005 & 1.000 & & & & \\
\hline $\begin{array}{l}\text { Developed } \\
\text { scripts? }\end{array}$ & 0.046 & 0.057 & 0.111 & 0.189 & -01119 & 0.504 & 0.116 & 1.000 & & & \\
\hline $\begin{array}{c}\text { Use } \\
\text { a laptop } \\
\text { computer? }\end{array}$ & 0.096 & -0.059 & 0.017 & -0.116 & -0.069 & -0.090 & 0.100 & -0.130 & 1.000 & & \\
\hline $\begin{array}{l}\text { Use } \\
\text { a GIS? }\end{array}$ & -0.092 & -0.067 & 0.337 & 0.371 & 0.203 & 0.057 & -0.116 & 0.046 & -0.166 & 1.000 & \\
\hline $\begin{array}{c}\text { Use } \\
\text { remotely } \\
\text { sensed } \\
\text { imagery? }\end{array}$ & -0.074 & 0.091 & 0.351 & 0.030 & 0.217 & -0.091 & 0.106 & 0.039 & 0.079 & 0.129 & 1.000 \\
\hline
\end{tabular}

Correlation values vary greatly, depending on the field activity and specific technology. On the basis of results of our statistical analysis, only weak correlations were obtained between researchers who collect samples in the field and the use of a GPS receiver $(-0.014)$, paper maps $(-0.030)$, a PDA $(-0.023)$, a tablet PC (0.054), a laptop computer (0.096), a GIS (-0.092), or remotely sensed imagery $(-0.074)$. Other than a slightly positive correlation with paper maps $(0.194)$, the same weak correlations were obtained between researchers who record field observations and the same specific technologies. Although weak correlations were obtained in responses related to field technology and recording field observations or collecting samples, relatively strong correlations were obtained between researchers who map environmental features in the field and the use of a specific technology. In addition to a strong correlation (0.504) between the use of a PDA and the creation of specialized scripts, other moderately strong positive correlations were obtained between researchers who map environmental features in the field and the use of remotely sensed imagery (0.351), a GIS (0.337), paper maps (0.233), and a GPS receiver (0.206). For these same researchers, a slightly positive correlation $(0.157)$ was obtained for tablet-PC use, and a slightly negative correlation $(-0.107)$ for PDA use, suggesting opportunities for the USGS in the development and implementation of tablet PCs for field mapping.

In addition to examining the potential correlations between certain field activities and the use of a specific technology, we also investigated whether the number of years of field experience correlates with field activities and (or) the use of a specific technology. Positive correlations may help guide technology development, outreach, and training efforts. We first compared the mean numbers of years of field experience between survey participants who answered "Yes" or "No" to the question whether they conducted certain activities or used specific technologies. Results (table 18) suggest that those scientists who map environmental features, use paper maps, use a tablet PC, use a field computer, or use remotely sensed imagery may have more years of field experience, whereas those who collect samples, use a GPS receiver, use a PDA, write their own scripts or applications, or use a GIS may have slightly fewer years of field experience. Because only one respondent did not record field observations, this activity cannot be fairly commented upon, except to say that apparently scientists at all levels of field experience do so.

None of the differences between means listed in table 18 , however, were particularly striking, and no obvious trend is evident toward greater or lesser technology use, 
information use, or field activity with regard to years of experience. To test whether or not the differences in means listed in table 18 are statistically significant, we ran two-sample $t$ tests. At the $\alpha=0.05$ confidence level, few of the means were statistically different (table 19), suggesting that increasing numbers of years of field experience does not generate either a strong inclination or disinclination to conduct certain field activities or use specific technologies. The exceptions to this general conclusion were mapping of environmental features in the field and use of tablet PCs while in the field, for each of which the mean age of "Yes" respondents was significantly higher than that of "No" respondents, suggesting that individuals with more years of field experience were more inclined to map environmental features in the field and to use a tablet PC. One possible explanation may be functional differences in staffing responsibilities within a project, where study sites may be established by senior researchers and then monitored by junior researchers. In other words, senior researchers map environmental features, while junior researchers collect site-specific data.

Finally, survey participants were asked in an open-ended question for additional comments related to mobile-computing technology to support USGS fieldwork (see app. A, question 29). In general, respondents were highly supportive for mobilecomputing technology at the USGS. Many fieldworkers are already using it and are interested in sharing their success stories and venting their frustrations with other USGS scientists. Respondents believed that better coordination and communication on the development and implementation of mobile-computing technology is needed both inside and outside the USGS In addition, some respondents requested training opportunities related to the use of this technology.

Although many respondents were supportive of its further promotion, respondents also expressed concerns with mobilecomputing technology at the USGS, primarily centered on the cost, weight, battery life, ease of use, and ability to withstand rugged field conditions. Many respondents expressed the need for tools that are simple enough to be modified in the field by researchers themselves without having to rely completely on specialized information-technology (IT) personnel. They also stated that the USGS should not pursue a common field-datacollection standard, thereby limiting researchers' efforts, or lock into one specific technology, because the private sector is creating new technology everyday. Several respondents expressed a concern that certain technologies or tools will be mandated by the bureau, and they were clearly resistant to that idea. To fully embrace new technology, respondents were also interested in access to specific digital data, such as base-map resources, weather data, real-time streamflow conditions, high-resolution stereopair aerial photographs, and gauging-site maps. Finally, many respondents expressed a concern about data backup and digital archiving and stated that paper-copy backups are critical.

\section{Discussion}

Fieldwork is the foundation for much USGS research, whether monitoring habitats, determining water quality, delineating wetland boundaries, or mapping geologic features (table 3). Regardless of topic, respondents record field observations, take samples, and map environmental features in the course of their USGS research - all activities where PDAs and tablet PCs could simplify data entry, database management, and field analysis.

Survey results suggest that although current use of these technologies is low, a potential exists for greater use of mobile-computing technology at the USGS. Results reveal many opportunities for technology sharing, whether easier access to common digital datasets or specialized scripts and data-entry forms. Although digital datasets already exist for many of the types and formats listed by respondents (table 16), evidently more work needs to be done to facilitate the use of these datasets by those USGS researchers who traditionally have not used a GIS and are unfamiliar with the associated file types. Additional data-delivery mechanisms that easily integrate with mobile-computing technology need to be developed for The National Map and Geospatial One-Stop to support USGS scientists. This work could, in addition, push the frontiers of geospatial archives like The National Map by framing it within a dynamic and mobile data delivery and collection system.

Nonetheless, many USGS scientists are quite comfortable with mobile-computing technology and GIS usage and are already developing specialized scripts for their research (see app. A). These more advanced users of mobile-computing technology now need mechanisms for sharing these scripts with those who do similar fieldwork, as well as a forum to support future script development. A potential next step for the USGS is to create an accessible archive of all current specialized scripts for PDAs and tablet PCs-a Web site that describes installation, use, lessons learned in the field, and the code - so that interested users have the opportunity to obtain, install, and modify scripts to fit their particular needs. Creation of this archive and virtual forum addresses the second objective for this study, which was to foster a community of technology developers and users. Survey participants already serve as a starting point for a larger and more coordinated group.

With regard to new areas for technology development and implementation, survey results suggest great opportunities for the use of PDAs and tablet PCs in USGS fieldwork. Most respondents spend significant periods of time in the field recording observations, collecting samples, and mapping environmental features but are not yet widely using mobile-computing technology. Many respondents still are primarily sketching field observations and maps in notebooks, on aerial photographs, and on topographic-map sheets. Some USGS scientists may basically be unaware of this new technology. For these scientists, simple scripts and training opportunities to showcase the benefits of mobilecomputing technology may increase its use and improve the efficiency and data consistency of USGS science. In addition, some researchers may know that a technology exists but not understand its full functionality, because survey results suggest that many fieldworkers are using tablet PCs just as larger versions of a PDA. For other researchers, mobile-com- 
Table 18. Mean number of years of USGS field experience between respondents who answered "Yes" or "No" on field activities and use of specific technologies.

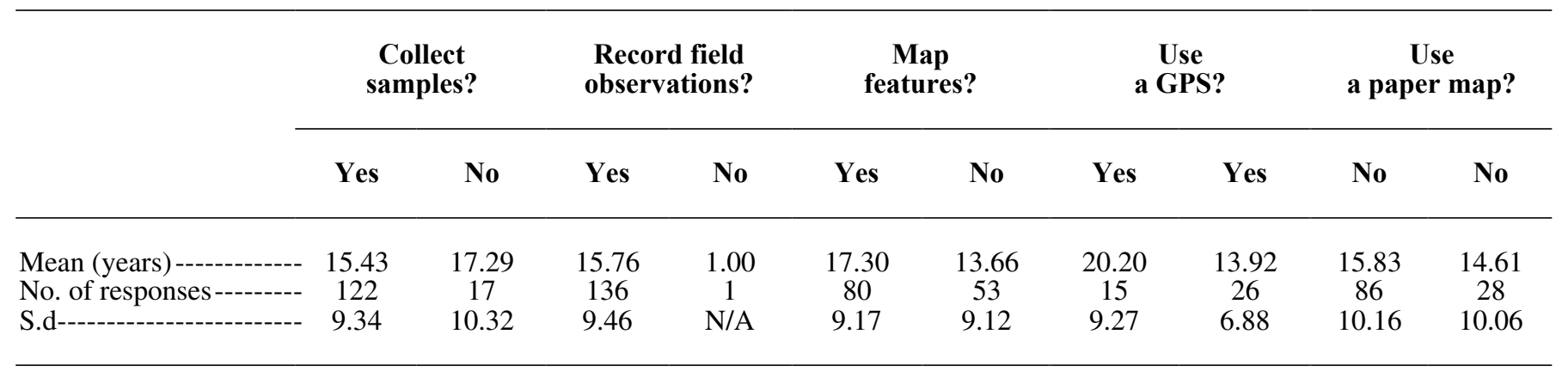

puting technology may not yet be at a level where it could be beneficial to them, possibly because it is too heavy or not rugged enough. For those researchers, the USGS should continue discussion on the potential for mobile-computing technology as the technology continues to become more sophisticated, more affordable, and more rugged. In this way, the USGS can position itself for more rapid adoption of this technology as the price, durability, and flexibility of these devices become more suitable for bureau purposes. As for specific opportunities, survey results suggest that applications which would have the greatest benefit for the bureau are additional PDA scripts for monitoring water quality and tabletPC scripts for geologic, ecologic and landcover mapping. Another next step for promoting mobile-computing technology at the USGS is to identify research areas that already have protocols for field-data collection; these protocols may easily be transferable to a digital format where mobile-computing solutions may be simple to develop and implement.

Overall, respondents support the use of mobile computing technology at the USGS and are interested in training opportunities and further discussions related to data archiving, access to additional digital data types, and technology application. Respondents were clear that they were seeking assistance in script development, training opportunities, and the ability to archive digital data but not in the bureauwide adoption of technology or data-collection standards if they do not already exist. Respondents seem hesitant to lock themselves into one technology or brand but instead seek assistance in navigating the multitude of private-sector options and in developing multiplatform scripts. With the ever-changing nature of technology, researchers seek help in distilling the options and information related to mobile computing and in developing solutions that are cost effective, light, long lasting, and modifiable by researchers and not just by IT specialists.

Survey results suggest that the USGS should determine where enterprise approaches to mobile-computing technology and better coordination of current application efforts are needed. Currently, only the WRD has an organized Field Computer Interest Group to support its researchers; the Biological Resources, Geology and Geography Disciplines all have only isolated efforts by individual researchers. Because so many
USGS scientists spend significant portions of the year in the field with small field crews, they are already devoting limited financial and human resources to developing time-saving technologies. The USGS could assemble a permanent technical team to support fieldworkers in their mobile-computing-technology needs. This team could also serve to coordinate and connect the various development projects across the bureau. Greater use of mobile-computing-technology could not only improve fieldwork but also reduce the amount of - or, at least, the time required for-postfieldwork data processing. A bureauwide investment could help minimize errors and redundancies in these efforts across the Nation.

On the basis of survey results, we recommend the following next steps with regards to the use of mobile-computing technology at the USGS:

- Determine additional issues and needs for those not adequately represented in this study, namely, individuals from the Central and Eastern Regions and from the Geologic Discipline;

- Compile an accessible USGS archive of all current specialized scripts for PDAs and tablet PCs;

- Determine specific needs for specialized USGS scripts related to water-quality monitoring for PDAs and geologic, ecologic, and landcover mapping for tablet PCs;

- $\quad$ Create data-delivery mechanisms within data archives like The National Map and Geospatial One-Stop that easily integrate with mobile-computing technology, so that USGS researchers can access critical digital datasets, including topographic maps, roads, aerial photographs, and elevation data; and

- Provide training opportunities on the use of mobilecomputing technology, specifically PDAs and tablet PCs, to support USGS field research.

By devoting bureauwide resources to coordinate the development and implementation of mobile-computing technology, the USGS will help its scientists devote more time to their research, rather than to the logistics of their research. Thus, scientists can fully focus their attention on work that furthers the USGS' mission. We hope that this survey serves as a starting point toward attaining this goal. 
Table 18. Mean number of years of USGS field experience between respondents who answered "Yes" or "No" on field activities and use of specific technologies-Continued.

\begin{tabular}{|c|c|c|c|c|c|c|c|c|c|c|c|}
\hline \multicolumn{2}{|c|}{$\begin{array}{c}\text { Use } \\
\text { a PDA? }\end{array}$} & \multicolumn{2}{|c|}{$\begin{array}{c}\text { Use } \\
\text { a tablet PC? }\end{array}$} & \multicolumn{2}{|c|}{$\begin{array}{c}\text { Write } \\
\text { scripts? }\end{array}$} & \multicolumn{2}{|c|}{$\begin{array}{c}\text { Use } \\
\text { a computer? }\end{array}$} & \multicolumn{2}{|c|}{$\begin{array}{c}\text { Use } \\
\text { a GIS? }\end{array}$} & \multicolumn{2}{|c|}{$\begin{array}{c}\text { Use remotely } \\
\text { sensed } \\
\text { imagery? }\end{array}$} \\
\hline Yes & No & Yes & No & Yes & No & Yes & No & Yes & No & Yes & No \\
\hline 14.54 & 16.18 & 20.20 & 15.12 & 13.92 & 15.83 & 16.11 & 13.75 & 14.99 & 16.54 & 17.82 & 14.71 \\
\hline 46 & 90 & 15 & 116 & 26 & 86 & 104 & 32 & 92 & 39 & 56 & 73 \\
\hline 7.46 & 9.97 & 9.27 & 9.06 & 6.88 & 10.16 & 9.60 & 9.14 & 8.92 & 10.03 & 9.72 & 9.11 \\
\hline
\end{tabular}

\section{Conclusions}

To better understand the opportunities and needs for mobile computing technology at the USGS, 144 researchers answered 65 questions about fieldwork goals, activities, and conditions, technology and data to support research, and postfieldwork data processing and analysis. Primary conclusions from this study include the following:

- $\quad$ Some mobile-computing-technology devices are already commonplace, such as digital cameras and GPS receivers, whereas others are not, such as PDAs and tablet PCs;

- The potential for PDA use in the USGS is high because 99 percent of respondents record field observations (primarily environmental conditions and water-quality data) and 87 percent of respondents take samples in the field (primarily water-quality data, water samples, and sediment/soil samples);

- The potential for tablet PC use in the USGS is also high because 59 percent of respondents map environmental features in the field, primarily by sketching in field notebooks, on aerial photographs, or on topographic-map sheets;

- Demand is high for a bureauwide effort to coordinate and develop efficient mobile-computing technology for USGS scientists because many researchers devote much time to fieldwork;

- Mobile-computing technology could also minimize the significant amount of time and cost that researchers devote to postfieldwork data processing; and

- Respondents support greater use of mobile-computing technology at the USGS and are interested in training opportunities and in further discussions related to data archiving, access to additional digital data types, and technology development in general.

\section{Acknowledgments}

This study was supported by the Advanced GIS-Based Field Mapping Techniques project managed by the USGS'
Geographic Analysis and Monitoring (GAM) and Cooperative Topographic Mapping (CTM) programs. We thank Sean Stone and Alan Vaughan for their assistance in creating the project Web site and the online survey, and Doug Muchoney, GAM Program Coordinator, and Tom Gunther of the GIO Enterprise Information Office for their assistance in advertising the survey within the bureau. Chris Brown and Sara Compton supplied the photograph of Zsolt Kahanzca in figure $1 B$; all other photographs were taken by Nathan Wood. Susan Benjamin, Tom Gunther, and Chris Brown provided insightful reviews of the manuscript.

\section{References Cited}

Edmondo, G.P., 2002, Digital geologic field mapping using Arcpad, in Soller, D.R., ed., Digital Mapping Techniques '02 - workshop proceedings: U.S. Geological Survey Open-File Report 02-370, p. 129134.

Pavlis, T.L., and Little, Jason, 2001, Using handheld personal computers as field data collection tools:

Table 19. Results of statistical $t$ test comparing years of USGS field experience with field activities and use of specific technologies.

\begin{tabular}{|c|c|c|c|}
\hline Years versus: & $N$ & $t$-stat & $P$-value \\
\hline 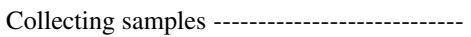 & 139 & 0.7596 & 0.4488 \\
\hline Recording field observations ${ }^{1}-$ & N/A & N/A & N/A \\
\hline Mapping features ${ }^{2}$ & 133 & -2.2456 & 0.0264 \\
\hline 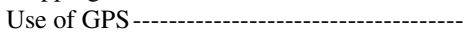 & 138 & 1.2584 & 0.2104 \\
\hline 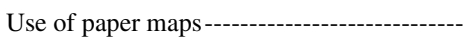 & 135 & -0.7351 & 0.2104 \\
\hline Use of PDA ------------ & 136 & 0.9798 & 0.3289 \\
\hline 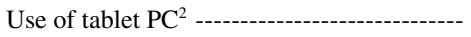 & 131 & -2.0375 & 0.0436 \\
\hline Writing scripts and (or) applications -------- & 112 & 0.8932 & 0.3737 \\
\hline Use of computer ----1 & 136 & -1.227 & 0.222 \\
\hline 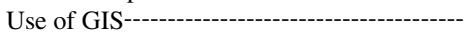 & 131 & 0.8757 & 0.3828 \\
\hline Use of remotely sensed imagery ----------- & 129 & -1.8657 & 0.0644 \\
\hline
\end{tabular}

${ }^{1}$ All respondents but one answered "Yes" to this question.

${ }^{2}$ Significant at the 5-percent-confidence level. 
some lessons learned in the school of hard knocks in the Wingate Wash project and related projects using fieldlog/fieldworker software exported to ArcInfo, in Soller, D.R., ed., Digital Mapping Techniques '01workshop proceedings: U.S. Geological Survey OpenFile Report 01-223, p. 115-121.

Stoller, D.R., ed., 2003, Digital Mapping Techniques '03-workshop proceedings: U.S. Geological Survey Open-File Report 03-471, 262 p. [URL http://pubs. usgs.gov/of/2003/of03-471/]

Williams, V.S., 2001, Conclusions from four years collecting digital map data using a PDA, in Stoller, D.R., ed., Digital Mapping Techniques ' 01 -workshop proceedings: U.S. Geological Survey Open-File Report 01-223, p. 125-126.

\section{Appendix A. Survey Questions and Results}

The following section summarizes the survey questions asked in this study. Response options for scripted questions and the percentage of each option received are also provided; open-ended questions are discussed in the main body of this report.

\section{Fieldwork}

1) What is the primary objective when you do fieldwork for your various projects? (open ended; see table 3)

2) Do you collect samples in the field?

$\begin{array}{ll}87 \% & \text { Yes } \\ 13 \% & \text { No } \\ 0 \% & \text { N/A }\end{array}$

a) What type of samples do you collect? (open ended; see table 4)

3) When at a fieldsite, do you record field observations?

$\begin{array}{ll}97 \% & \text { Yes } \\ 1 \% & \text { No } \\ 1 \% & \text { N/A }\end{array}$

a) What type of field observations do you record? (open ended; see table 4)

4) Do you map features when in the field?

$\begin{array}{ll}57 \% & \text { Yes } \\ 39 \% & \text { No } \\ 4 \% & \text { N/A }\end{array}$

a) What do you map? (open ended; see table 5)

b) How do you do map features? (open ended; see table 5)

5) Do you use a Global Positioning System (GPS) receiver in the field?

$\begin{array}{ll}88 \% & \text { Yes } \\ 12 \% & \text { No } \\ 1 \% & \text { N/A }\end{array}$

a) What is the GPS receiver used for in the field? (open ended; similar responses are into categories)

\begin{tabular}{|c|c|}
\hline Use of GPS & No. of responses \\
\hline Location/navigation------------- & 76 \\
Garmin product----------------- & 28 \\
Trimble product----------------- & 5 \\
Various-------------------- & 5 \\
Rockwell product-------- & 3 \\
"See previous answer"--------- & 1 \\
Ashtech product----------------- & 1 \\
Card in pocket PC------------- & 1 \\
Sutron product---------------- & 1 \\
Teletype product----------------- & 1 \\
Setting time stamp------------- & 1 \\
\hline
\end{tabular}

6) Do you use a paper map in the field?

$\begin{array}{ll}76 \% & \text { Yes } \\ 22 \% & \text { No } \\ 3 \% & \text { N/A }\end{array}$

a) What type(s) of map(s) do you use, and what do you use them for? (open ended; see table 8)

b) What map scale do you typically use? (open ended; see table 8)

7) Do you take photographs while in the field?

$\begin{array}{ll}97 \% & \text { Yes } \\ 2 \% & \text { No } \\ 1 \% & \text { N/A }\end{array}$

a) Do you use a digital or film camera? (write in; similar responses are into categories)

$\begin{array}{ll}90 \% & \text { Digital } \\ 4 \% & \text { Film } \\ 2 \% & \text { Both digital and film } \\ 4 \% & \text { No response }\end{array}$

8) Do you use a personal digital assistant (PDA) in the field?

$\begin{array}{ll}33 \% & \text { Yes } \\ 64 \% & \text { No } \\ 3 \% & \text { N/A }\end{array}$

a) How do you use the PDA in the field? (open ended; see table 9)

9) Do you use a tablet PC in the field?

$\begin{array}{ll}11 \% & \text { Yes } \\ 83 \% & \text { No } \\ 6 \% & \text { N/A }\end{array}$

a) How do you use the tablet PC in the field? (open ended; see table 9)

10) Have you developed specialized scripts or applications for your field use of PDAs or tablet PCs?
$19 \% \quad$ Yes
$62 \% \quad$ No
$19 \% \quad \mathrm{~N} / \mathrm{A}$

a) What are the main features of your script or application? (open ended; raw responses)

- Calculations for navigation, fuel consumption, heat index, tides and currents, misc. [sic] others. - Checking accuracy of data entered on forms. 
- Collect data in the way we need the data collected.

- Created specialized scripts within Pendragon to address a variety of situations. Not sure what you mean by "main feature."

- Creation of forms.

- Data dictionaries for Trimble GeoXT.

- Datalogger and telemetry programs.

- Downloading data from a serial port, converting it from hex to text, and giving a quick summary of the file.

- Dropdown lists, GPS download, automatic look up of next ID number, weight and length range proofing.

- Equipment inventory_ —standardized" field notes - instrument calibration tracking...

- Excel document to store stream-discharge-meassurement data and to automatically compute the results.

- Field notes and well/pump electric/gas powercoefficient computations.

- For previous work (FWS Kodiak NWR brownbear study) I developed scripts in Pendragon soft ware for use on Palm OS PDAs to enter brownbear observations and synchronize them to a MS Access database.

- GPS connectivity, record observations, Java so it runs on Pocket PC or Linux PDAs, easy for me to modify or adapt to new projects.

- I am the author of PCFF. This software allows you to collect and process water-quality data, record meter-calibration information, print out required forms, and allows for the automated update of the data into the NWIS database.

- Menu-driven forms and combo boxes.

- Pendragon forms.

- Plot lat/long coordinates in ArcMap.

- Print field notes, produce database input file to $\log$ in sample.

- Question is too broad for a mere ecologist. We have data fields, and we enter data.

- Stated in previous answer.

- Streamflow calculator.

- To calculate levels data.

- Unix scripts to process GPS data: Excel spread sheets to help reduce gravity data. Written for laptop, not tablet PC or PDA.

- USGS ARMI program has developed numerous specific scripts to allow our specialized use of PDAs in the field. The San Diego field station has been instrumental in this and would be able to provide details of these scripts.

- We use Pendragon forms on a Palm OS PDA to store our field measurements and observations.

- We worked hard to develop script to use ARC on a Pocket PC. The idea was that we could import a digital map image (using MRSID) and the Pocket PC would use the attached GPS to show our location and record the location of birds that we observed (by pointing on the screen to the location of the bird that we saw). At each screen contact, a popup menu would come up that would allows us to enter species names, etc., for each data record. After a year of trial, we gave up because it was still faster and more efficient to use hardcopy maps in the field and enter the data into ARC later. I think that this method has general promise, but we would have needed someone with real programming skills to get it fast and bug free.

11) Do you use a computer while in the field?

$\begin{array}{ll}74 \% & \text { Yes } \\ 24 \% & \text { No } \\ 3 \% & \text { N/A }\end{array}$

a) What type of operating system does your field computer use?

$69 \%$ Windows based

$1 \%$ MacOS based

$3 \%$ Other-MS-DOS laptop

$27 \%$ No response

b) How rugged does this computer need to be?

$40 \%$ Needs to be waterproof or environmentally sealed

$33 \%$ Not rugged, would be used in controlled environment

$27 \%$ No response

12) How many days of the year do you spend in the field?

$\begin{array}{ll}4 \% & <1 \text { week } \\ 27 \% & <1 \text { month } \\ 40 \% & 1-3 \text { months } \\ 23 \% & 3-6 \text { months } \\ 5 \% & >6 \text { months } \\ 1 \% & \text { No response }\end{array}$

13) What is the average length of an individual field investigation?

$\begin{array}{ll}22 \% & 1 \text { day } \\ 44 \% & 1 \text { week } \\ 10 \% & 2 \text { weeks } \\ 6 \% & 1 \text { month } \\ 13 \% & \text { Longer than } 1 \text { month } \\ 6 \% & \text { No response }\end{array}$

14) How many people go with you when you do your fieldwork?

$\begin{array}{ll}28 \% & \text { No one else } \\ 33 \% & \text { One person } \\ 21 \% & \text { Two people } \\ 6 \% & \text { Three people } \\ 11 \% & \text { Four or more people } \\ 1 \% & \text { No response }\end{array}$

15) Do you travel on foot while in the field?

$\begin{array}{ll}78 \% & \text { Yes } \\ 21 \% & \text { No } \\ 1 \% & \text { N/A }\end{array}$

a) How far do you typically travel on foot away from a motorized vehicle? (open ended; see table 9)

\section{Office Work}

16) After returning from the field, do you (or does someone in your office) enter your field data into a computer system? 
$68 \% \quad$ Yes, I enter the data

$22 \%$ Yes, someone else enters the data for me

$7 \% \quad$ No

3\% No response

Responses broken down by respondents'

USGS discipline:

\begin{tabular}{|lccc|}
\hline \multicolumn{1}{|c}{$\begin{array}{c}\text { Respondents' } \\
\text { discipline }\end{array}$} & $\begin{array}{c}\text { Yes, I enter the } \\
\text { data }\end{array}$ & $\begin{array}{c}\text { Yes, someone } \\
\text { else enters }\end{array}$ & No \\
\hline Biological Resources & 10 & 15 & 5 \\
Geography & 11 & 2 & 1 \\
Geology & 14 & 4 & 1 \\
Water Resources & 62 & 11 & 3 \\
\hline
\end{tabular}

a) How many hours are spent doing this task after a field session?
$24 \% \quad 1$ day
$24 \% \quad 1$ week
$10 \% \quad 2$ weeks
$11 \% \quad 1$ month
$8 \% \quad$ Greater than 1 month
$23 \%$ No response

b) What operating system does the computer

system have?

$79 \%$ Windows

$6 \%$ UNIX

$1 \%$ MacOS

$1 \%$ Other

$12 \%$ No response

17) Back in the office, do you record your field observations or mapped features manually on a paper map or photo?

$\begin{array}{ll}25 \% & \text { Yes } \\ 68 \% & \text { No } \\ 7 \% & \text { N/A }\end{array}$

18) Do you use a geographic information system (GIS) in your research?

$\begin{array}{ll}64 \% & \text { Yes } \\ 30 \% & \text { No } \\ 6 \% & \text { N/A }\end{array}$

a) What type of GIS software is used? (open ended; similar responses are grouped into categories)

\begin{tabular}{|c|c|}
\hline $\begin{array}{l}\text { Category of } \\
\text { GIS software }\end{array}$ & $\begin{array}{c}\text { No. of } \\
\text { responses }\end{array}$ \\
\hline Arc (unspecified) - & 5 \\
\hline ArcCatalog ------- & 1 \\
\hline ArcGIS------- & 34 \\
\hline ArcIMS ---- & 1 \\
\hline 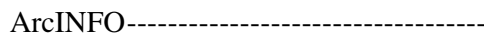 & 16 \\
\hline 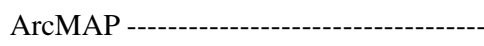 & 20 \\
\hline ArcPad ------- & 4 \\
\hline ArcView ------- & 23 \\
\hline Don't know-----. & 2 \\
\hline 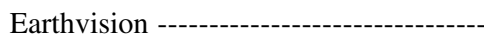 & 1 \\
\hline ENVI ------1 & 5 \\
\hline
\end{tabular}

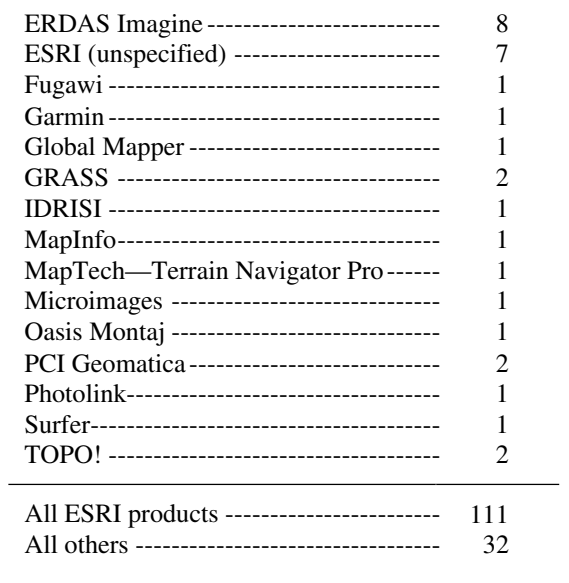

b) What is GIS used for in your research? (open ended; see table 13)

19) Do you use remotely sensed imagery in your work?

$\begin{array}{ll}40 \% & \text { Yes } \\ 52 \% & \text { No } \\ 8 \% & \text { N/A }\end{array}$

a) What kind of remotely sensed imagery do you use? (write in; similar responses are grouped into categories)

\begin{tabular}{|c|c|}
\hline $\begin{array}{c}\text { Remote-sensing } \\
\text { type }\end{array}$ & $\begin{array}{l}\text { No. of } \\
\text { responses }\end{array}$ \\
\hline Aerial photography---------- & 15 \\
\hline Landsat--------- & 15 \\
\hline 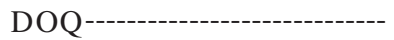 & 13 \\
\hline Lidar--------- & 11 \\
\hline Satellite ------------------------ & 11 \\
\hline Other; N/A ----------------------- & 6 \\
\hline GOES -------------------------- & 4 \\
\hline 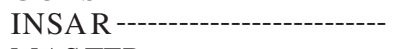 & 4 \\
\hline MAS TER ---------------------- & 4 \\
\hline ASTER------------------------ & 3 \\
\hline Stage ------------------------ & 3 \\
\hline Hyperspectral ----------------- & 2 \\
\hline IR----- & 2 \\
\hline Quickbird ------- & 2 \\
\hline SPOT ------------------------ & 2 \\
\hline Aeromagnetic --------------- & 1 \\
\hline AirSAR --------------------- & 1 \\
\hline Altimetry---------------------- & 1 \\
\hline 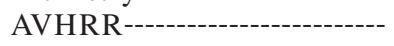 & 1 \\
\hline AVIRIS------------------------- & 1 \\
\hline 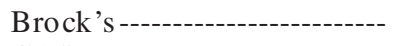 & 1 \\
\hline CAS I -------------------------- & 1 \\
\hline CIR---------- & 1 \\
\hline FLIR------------------------- & 1 \\
\hline 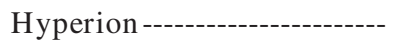 & 1 \\
\hline 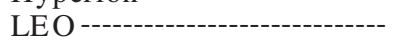 & 1 \\
\hline 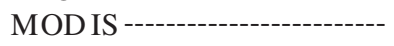 & 1 \\
\hline NCEP---------------------------- & 1 \\
\hline Radar ---------------------------- & 1 \\
\hline RadarS at ------------------------ & 1 \\
\hline SAR-derived DEM---------- & 1 \\
\hline Side-scan sonar--------------- & 1 \\
\hline Telemetry-------------------- & 1 \\
\hline Thermal --------------------- & 1 \\
\hline
\end{tabular}


b) What do you use it for? (open ended; see table 15)

20) Having certain types of data in the field can sometimes make fieldwork easier. Do you currently use any of the following types of information in your fieldwork, and would you use it if it were available? (see table 16)

\section{Background Information}

21) Job title (open ended; see table 1)

22) USGS discipline

$22 \% \quad$ Biological Resources

$10 \%$ Geography

$0 \% \quad$ Geospatial Information Office

$14 \%$ Geology

$54 \% \quad$ Water Resources

23) Region

$\begin{array}{ll}12 \% & \text { Eastern } \\ 19 \% & \text { Central } \\ 68 \% & \text { Western } \\ 1 \% & \text { No response }\end{array}$

24) Science Center (open ended; results dropped because most responses were incomplete)

25) What type of landscape or environment do you typically work in when you are in the field? (open ended; see table 2)

26) How many years have you been doing field research? (open ended; see fig. 1)

27) Name (write in; not disclosed to maintain participant confidentiality)

28) Phone number (write in; not disclosed to maintain participant confidentiality)

29) Is there anything else you would like to tell us related to the development of advanced GIS-based field data-collection and mapping techniques for USGS research? (open ended; raw responses)

- "One size does not fit all." Each project is different, and the data that need to be collected will vary, especially from researcher to researcher. Tools that are loose enough to be configured easily and deployed at the researcher level are the best. Simple tools that use the conventional computer technology (not the latest) are best because the "bugs" have mostly been worked out of them. Persons developing these applications should be more biologist than programmer or database person or IT type.

- A bottle labeler that would print out barcoded labels, along with the verbal sample info from the PDA or tablet, could be very useful.

- A GIS map of a gauging site would be very useful. Critical points for the station could be precisely plotted, which would aid technicians and others to find RMs, etc.

- A system needs to be developed that would incorporate real-time Internet-based GIS of streamflow conditions using ArcIMS that could be accessed via wireless handheld devices in the field for the access, retrieval, and immediate storage of field data. This system would be accessible via any Web browser (including the PDA browser) and contain basic online analytical GIS tools and data for basic query and analysis. The handheld devices should be robust and standardized with USB and infrared data-exchange technology.

- All notes take on field trips are done with pen and paper, then they need to be transferred to electronic form. Eliminating the paper step would save time.

- Any spatial data collected today most likely will involve the use of GPS technology, where the spatial data are georeferenced to $3 \mathrm{D}$ positions determined in real time or determined from postprocessing of the raw observational data. The 3D positions (lat, long, and ellipsoid height (h) and, if known, the geoid height (N) for the work area, elevations $(\mathrm{H})$ ), where the accuracy required for the positions may be dependent on the purpose for the spatial data collected, and distance relationship to adjacent spatial data collected in the work area. The metadata should include, as a minimum, methodology used for the GPS-determined coordinates, data/time of measurement (or when spatial data are collected), an indication of position accuracy $(1 \sigma[67 \%]$ or $2 \sigma[95 \%]$ confidence level), the datum (such as for NAD1983 and ITRF2000), and other appropriate information required for historical records.

- Better training is needed.

- Cost of data-collection systems is a concern, as well as data backup.

- Don't limit the way people can collect the information they need by writing some policy that no one will read anyway.

- For me to use such technology, it would have to be very rugged and completely waterproof. It would also need to be relatively cheap so I could afford to lose one without bankrupting a project budget.

- Foresee PDAs running into PCs with miniaturization - would recommend planning for that eventually by not locking in to a certain technology.

- GPS accuracy still presents problems in many environments - forcing reliance on paper maps and past experience. We will be developing digital field datacollection protocols as part of interdisciplinary research efforts in the Everglades. These will likely make use of PDAs. I typically record crucial measurements made by specialized instruments (i.e., ceptometers) on paper at the same time data are being captured by the device because their data logging capabilities remain primitive and are susceptible to failure in harsh physical environments.

- Hardcopy prints of aerial photos on photographic paper cannot be replaced in the digital world without a great deal of expense and effort. Aerial photos are the single biggest and best resource for geologic mapping, and must be used stereoscopically. We now order aerial photos from other agencies, even though the USGS has the biggest and best library. What a shame that resource is no longer available! 
- I am dismayed by how far behind the USGS is in investigating and acquiring modern ways of collecting field data. It is very difficult to get funding for items such as tablet PCs, which I think would facilitate and streamline data collection. It would also be incredibly helpful to have 3D stereo capabilities, such as Stereo Analyst for ArcGIS, and rectified aerial photography to use in such systems. We need to move away from dedicated PG2 plotter labs to desktop capability for 3D mapping and data analysis.

- I am interested in using our field data in conjunction with space-based systems.

- I am very pleased with Trimble GPS products for fieldwork. The Trimble GeoXT allows a background raster and a vector data file with a data dictionary. Data collection and management with the GeoXT is efficient in the field and in the office.

- I am very satisfied with my system now and believe it is more efficient for map production. Support staff also critical for me in preparing digital geologic maps. Comment: only one choice offered in survey questions (e.g., I use both paper and digital topos).

- I feel that there is a definite use for PDAs in science, not just in the GIS-based field data collection or mapping techniques but for a variety of other reasons. However, it has sometimes proven difficult to get support from the manufacturers of these machines, so it seems that we are individually going at it alone. I would like to see a greater push for a more open communication that can involve idea sharing, technical advice, etc.

- I found that "off the shelf" GIS software is more user friendly in the field. A GIS application that would easily synchronize field and office data would be of great value.

- I have seen applications in use regarding groundwater wells, their location, and the associated data. Impressive!

- I have used PDAs in fieldwork before, and they were extremely useful and applicable for the kind of research that we do. However, I think that lack of money and perceived electronic difficulties may hamper the switch from conventional to digital forms of data storage.

- I heartily recommend pursuing advanced methods for field data collection. We've needed more of these tools for some time now. The team I'm working with is currently interested in acquired a Trimble GeoXT for the field. We would like to be able to segment imagery using eCognition software, upload the resulting polygons into the device, and use this digital data directly in the field to automate collection of all the information we're acquiring.

- I support the effort!

- I would appreciate the availability of a tablet PC into which data could be input and later uploaded to GWSI, QWDATA, and which has voice-recognition software.
- I would love to use a small rugged computer in the field daily and compile directly to digital, rather than use mylar compilation and digitizing later as a substitute. BUT I am a Mac diehard, and the working conditions (often driving rain, dirt and rocks on hands and all over pack, etc.) make it hard to believe any system will be rugged enough to survive (whereas a plastic map case can be hidden under your rainjacket to write on and bends when large samples impinge on it in your backpack while falling $6^{\prime}$ down a cliff.)

- I'd be more likely to use pen tabs more consistently for field mapping if they were a little lighter, more rugged, screens worked better in broad daylight, and batteries held charges longer.

- I've spent more time developing PDA applications for other projects, primarily Landfire, than for my own fieldwork. In working with other scientists, I've found that a full-blown GIS app is usually far more than is needed in the field. The ability to compile GPS, date/time, field photos, and observations digitally into a database is the most important aspect. Having GPS-connected digital maps and imagery in the field is a bonus. I was unable to attend the San Diego conference, but I am very interested in the development side of this issue.

- If you develop wonderful programs for us to use in the field, please do so, to the greatest extent possible, in relatively low level programs that we can have easy access to while in the field. We DON'T want to enter data in ArcPad or ArcMap while in the field. We will use something like ArcPad for recording a bit of navigation/location data, but the data WILL be entered in something else. We have been working on small standalone programs in something like HanDbase for recording vegetation data. I like the idea of recording in Access, using specialty Visual Basic programs (or something similar). The benefit of recording data in what I'm calling low-level software programs is that we can modify things in the field. If we notice something that was not anticipated, we can add a field or category on the fly and collect that data. If we have a data-entry program written by someone in Tim-buck-too using some high-level and very expensive program, then we cannot add the additional field. Having a data-entry program that is easily modifiable in the field would be the bee's knees.

- It has been my experience that a wide range of reliability exists in equipment, software applications, data capture, etc. I am interested in developing customized methods for recording observations and landcover classifications

- It has got to work under heavy tree cover and brush cover and in narrow canyons, or we won't use it, as it causes more trouble than it solves when locations are degraded owing to poor satellite constellations. Also, I can drop a notebook and pick it up again, and it will still work. Most PDAs are not that durable. And a paper map does not pose the continuing archival chal- 
lenges of the digital age, where so-called "permanent" media is woefully temporary. The archive problems are real and are not being adequately addressed by those who would rush us into a digital age. Digital information is great for timely transmission back to the bosses at the office, but hardcopy backup is essential, in my opinion. I achieve that with paper maps.

- Nice to have easier access to high-resolution, contactprint DOI aerial photography; closing EROS was a great loss.

- Just to mention that we used mixed platform. Most of the GIS and data collection is Windows based. I use Mac OS for regular work.

- Lack of availability of stereopair aerial photographs seriously impairs the ability to perform geomorphic research. Until the resolution of the printed stereopair aerial photograph can be fully reproduced digitally (printed copies are viewed with magnifying glasses, not simply with the unaided eye), geomorphic research must rely heavily upon film-based printed aerial photographs. The loss of the ability of the USGS to provide these has seriously hindered research where these photographs are unavailable from other agencies.

- No, but I will like to see what comes of your survey and what others are using. I believe we could all benefit by being better informed as to what other USGS researchers are using in their work in this regard.

- Nope, just hope we get to use it soon. Using a PDA would cut down on the amount of data-entry error, increase the legibility of data entry, and reduce the risk of failing to fill out data forms in their entirety.

- Regarding locating thermal features in Yellowstone Park: many features are within meters of each other, so high GPS accuracy is needed; our Garmin 3+ unit is sometimes of marginal accuracy for this purpose.

- Sometimes high-tech options aren't really needed in the field. Good old accurate and careful sample collection is really the best type of fieldwork. I used a PDA once, and it lost all my data, so now I use my old dependable field notebook.

- Tablet PCs and Ipaqs/PDAs with ArcPad, or similar software, are still a bit too expensive and not rugged enough for my needs. I use a low-end, inexpensive PDA for data entry because the batteries last a long time, and if I lose it or it breaks, it's no big loss, plus it's very lightweight. Ruggedized tablet PCs would be great if they didn't weigh so much and have such short battery lives. Much of my work requires bushwhacking through forests, so lighter, cheaper, and more rugged is better.

- American Fisheries Society's Computer User Section has PDA scripts available for download for fisheries applications.

- The cost! We would do much more with digital data collection if there was money to do it. We could be much more efficient if there was a way to upgrade our equipment!

- There exists some neat software which incorporates orthoquad/aerial imagery with a digital camera that has a GPS device embedded in it. The user takes a pic. [sic], and it shows up on the map with date/time/ aspect/link to photo.

- Trimble currently has a great hand-held device for compiling field data needed for many of our landcover- and vegetation-mapping projections. This device would be a great addition and timesaver for the work we do.

- Moving toward the tablet PC. Will replace the laptop or at least supplement it. I am currently alpha-testing one now.

- We use a hand-held device from YSI called a 650. This device is able to log data from a YSI probe and a GPS unit at the same time. This is a very valuable tool for gathering data for salinity maps.

- We wish that we could have access to USGS basemap resources to better analyze our results.

- We're excited by the possibilities of tablet PCs and tablet Collector-PC base stations. We'd like to be able to log in our samples from the field, using a phone.

- Weather information is the single most important determinant to our ability to work safely in the marine environment.

- Whatever device I take to the field must tolerate a lot of dust, heat, rainstorms, dropping on rocks; it must be easy and cheap to replace; it must be lightweight (no more than $1 \mathrm{lb}$ ); it must have a large screen ( 8 by 8 in. at least). Unless it meets these criteria, it's useless and a waste of time.

- Like to see an easily usable system for taking standard notes for a gauge visit and discharge measurement on PDA.

- Yes, we need better development of sunlight suitable screens, EXTREMELY portable (lightweight), durable (rain, surf, heat), and multipurpose units to collect GPS data and record or map information. Good if linked to camera, too, and having good data-entry capabilities. Currently, we use codes to facilitate digital entry in the field on small units, or use the reliable old notebooks. 


\section{Appendix B. Survey Cover Letter}

Supervisors, managers, team leaders: Please provide a copy of this memorandum to your employees without access to electronic mail.

\section{MEMORANDUM}

June 23, 2005

To:

All USGS Employees

From: Doug Muchoney, Geographic Analysis and Monitoring Program

Tom Gunther, Enterprise Information Program

Nathan Wood, Western Geographic Science Center, Geography Discipline

Subject: $\quad$ Field Data Collection and Mapping Survey

The Geographic and Analysis Monitoring Program is conducting a survey to document field data collection and mapping activities being conducted throughout the USGS and to identify mobile-computing opportunities for field researchers. This survey is part of a larger project to develop field data-collection and mapping tools that capitalize on emerging technologies, such as personal digital assistants (PDAs) and tablet PCs.

Your responses to this survey will help us identify ways in which PDAs and tablet PCs can be used in combination with software and scripts to facilitate data entry, management, and integration, as well as mapping and postfieldwork processing and analysis. It will identify opportunities for sharing and measure support for a bureauwide team to develop the concept of mobile computing as an aid to USGS field science.

We ask USGS employees involved in fieldwork activities in all disciplines and all regions that are using or planning to use mobile-computing technology to complete this survey. The success of this study and the future development of advanced GIS-based tools are highly dependent on the cooperation and involvement of other USGS scientists. We thank you for your contribution to this effort.

The survey is brief ( $\sim 15$ minutes) and can be filled out by linking to the following URL: http://internal.wr.usgs.gov/geography/FieldsToolsSurvey/. 
